\title{
Currency crises early warning systems: why they should be dynamic
}

Citation for published version (APA):

Candelon, B., Dumitrescu, E-I., \& Hurlin, C. (2010). Currency crises early warning systems: why they should be dynamic. METEOR, Maastricht University School of Business and Economics. METEOR Research Memorandum No. 047 https://doi.org/10.26481/umamet.2010047

Document status and date:

Published: 01/01/2010

DOI:

10.26481/umamet.2010047

Document Version:

Publisher's PDF, also known as Version of record

\section{Please check the document version of this publication:}

- A submitted manuscript is the version of the article upon submission and before peer-review. There can be important differences between the submitted version and the official published version of record.

People interested in the research are advised to contact the author for the final version of the publication, or visit the DOI to the publisher's website.

- The final author version and the galley proof are versions of the publication after peer review.

- The final published version features the final layout of the paper including the volume, issue and page numbers.

Link to publication

\footnotetext{
General rights rights.

- You may freely distribute the URL identifying the publication in the public portal. please follow below link for the End User Agreement:

www.umlib.nl/taverne-license

Take down policy

If you believe that this document breaches copyright please contact us at:

repository@maastrichtuniversity.nl

providing details and we will investigate your claim.
}

Copyright and moral rights for the publications made accessible in the public portal are retained by the authors and/or other copyright owners and it is a condition of accessing publications that users recognise and abide by the legal requirements associated with these

- Users may download and print one copy of any publication from the public portal for the purpose of private study or research.

- You may not further distribute the material or use it for any profit-making activity or commercial gain

If the publication is distributed under the terms of Article $25 \mathrm{fa}$ of the Dutch Copyright Act, indicated by the "Taverne" license above, 
Bertrand Candelon, Elena-Ivona

Dumitrescu, Christophe Hurlin

Currency Crises Early Warning Systems: why they should be Dynamic

$\mathrm{RM} / 10 / 047$

\section{METEOR}

Maastricht University School of Business and Economics

Maastricht Research Schocl of Economics

of Technology and Organization

\section{PO. Box 616}

NL - 6200 MD Mastricht

The Netherlands 


\title{
Currency Crises Early Warning Systems: why they should be Dynamic
}

\author{
Bertrand Candelon* Elena-Ivona Dumitrescu ${ }^{\dagger} \quad$ Christophe Hurlin ${ }^{\ddagger}$
}

September 2010

\begin{abstract}
This paper introduces a new generation of Early Warning Systems (EWS) which takes into account dynamics within a system composed by binary variables. We elaborate on Kauppi and Saikonnen (2008), which allows to consider several dynamic specifications and to use an exact maximum likelihood estimation method. Applied so as to predict currency crises for fifteen countries, this new EWS turns out to exhibit significantly better predictive abilities than the existing models both within and out of the sample.

Key words: dynamic models, currency crisis, Early Warning System.

J.E.L. Classification: C33, F37
\end{abstract}

*b.candelon@maastrichtuniversity.nl, Maastricht University, School of Business and Economics, Department of Economics,

†elena.dumitrescu@univ-orleans.fr, University of Orléans and Maastricht University, Laboratoire d'Economie d'Orléans (LEO),

${ }^{\ddagger}$ christophe.hurlin@univ-orleans.fr, University of Orléans, Laboratoire d'Economie d'Orléans (LEO) 


\section{Introduction}

The recent subprime crisis has renewed the interest for Early Warning Systems (EWS). In principle, they should be able to ring before the occurrence of a financial crisis letting enough time for authorities to implement adequate rescuing policies to prevent or at least to smooth the perverse effects of the turmoil. Unfortunately, the existing EWS have remained silent at the edge of the recent financial crisis, leading researchers to renew their models. ${ }^{1}$ This paper follows this objective emphasizing the importance of crisis dynamics for the new generation of EWS.

At first sight, understanding why detecting a crisis appears so difficult is fastidious as forecasting techniques have substantially improved over the last decades. This difficulty actually lies in the specificity of EWS, that aim at accurately detecting the occurrence of a crisis, which is by essence a binary variable taking the value of one when the event occurs, and the value of zero otherwise. Hence, it is not possible to directly implement the methods proposed in times series econometrics such as vector autoregression. Thus, following Kaminski, Lizondo and Reinhart (1998) (hereafter KLR), the first EWS was elaborated upon a signalling approach. Using a large set of potentially informative variables ${ }^{2}$, they identified a threshold beyond which a crisis is signaled. The properties of such an EWS clearly depend on this cut-off point. KLR estimated it as the threshold value that minimizes the ratio between the number of crises incorrectly and correctly detected, also called the noise-to-signal ratio. ${ }^{3}$ Once the variable specific threshold is determined, it is possible to build an aggregate indicator as a weighted combination of the variables, where each weight corresponds to the inverse of the associated noise to signal ratio. Hence, the so built EWS should exhibit a positive trend as the occurrence of a crisis increases.

Berg and Patillo (1999) (hereafter BP) proposed to use a static panel probit model as an alternative to the signalling approach. Hence, the binary crisis variable is treated as endogenous and explained by a set of macroeconomic variables. Evaluation criteria, such as the quadratic probability score (QPS) and the log probability score (LPS), indicate that their EWS exhibit better forecasting abilities (within and out of the sample) than the KLR one. Several extensions have been proposed: Kumar et al., (2003) advocate the use of panel logit instead of panel probit. Fuertes and Kalotychou, (2007) and Berg et al., (2008) analyze the presence of country clusters and their consequences for the EWS. Bussiere and Fratzscher (2006) suppose that a post-crisis specific period may be present, and consider the crisis as a ternary variable instead of a binary one, thus developing a multinomial logit EWS (Bussiere

1. See Rose and Spiegel (2010)

2. KLR consider 15 variables characterizing the domestic macroeconomic conditions, the external position and the financial sector of the considered countries.

3. Alternative estimation methods are available. See Candelon et al. (2009) for a discussion of this point. 
and Fratzscher, 2006). Moreover, as the estimation methods for panel limited dependent variables are quite standard and available in almost all econometric softwares, this type of EWS has been extensively implemented in applied studies.

Nevertheless, both previous EWS are static and assume that the probability to exit a crisis period depends only on a set of macroeconomic variables, representing the implemented economic policies. This assumption is not supported by most empirical studies which show that the longer a country is in a crisis period, the higher the probability to exit the crisis will be, whatever the political reaction (see Tudela, 2004). Besides, Berg and Coke (2004) showed that EWS are per nature autoregressive, as they should ring not only one period before the occurrence of a crisis but during $j$ periods, where $j$ is the forecast horizon. Hence, it appears difficult for a static model to reproduce such a property.

To overcome the absence of dynamics, another mainstream of the literature proposes EWS elaborated on Markov-switching models (MS hereafter) (Abiad, 2003; Martinez-Peria, 2002; Fratzcher, 2003). This type of EWS can take into consideration dynamic processes which are specific to the crisis or non-crisis regime. Nevertheless, as these models are shaped for continuous variables, they cannot be used in case of the crisis binary variable, without imposing another ad hoc threshold. Instead, they consider a market pressure index, which is a continuous indicator of the stress faced by a country's currency. Although this approach is per se interesting, it has been shown by Candelon et al. (2009) that its predicting abilities are lower compared to the BP EWS. Moreover, a panel version of MS model is, to the best of our knowledge, not available.

Therefore, our paper proposes a new generation of EWS which reconciles the limited dependent property of the crisis variable and the dynamic dimension of this phenomenon. Particular attention is given to the specification and the estimation of such models. Actually, the dynamics of crises can be apprehended in several ways. First, it can be included as a lagged binary crisis variable. Thus, the EWS to be estimated looks like an autoregressive (AR) binary model, where the lagged binary variable summarizes all the past information of the system. Second, dynamics can be introduced via the past probability of being in a crisis regime. Finally, the two previous specifications should allow for the presence of past macroeconomic variables representing the economic policies experienced by a certain country. Given all these different specifications, the estimation methodology proposed should be flexible enough to allow for specification tests. It is the recent paper of Kauppi and Saikonnen (2008) that proposes an exact Maximum Likelihood estimation fitted to all these model specifications. ${ }^{4}$ Beyond being easy to program in most common econometric softwares ${ }^{5}$ and not time intensive (results are obtained in a few second), this framework allows to detect

4. A previous attempt to estimate one specific dynamic specification has been proposed by Falcetti and Tudela (2006) using a smoothly simulated likelihood estimation.

5. All Matlab program are available from the authors upon request. 
the best dynamic specification via the well-known information criteria. While Kauppi and Saikkonen (2008) consider exclusively a time series framework, we extend it to a fixed effects panel based EWS by elaborating on Carro (2007).

In an empirical analysis, we aim to build a currency crisis EWS for a sample of fifteen emerging countries. The predictive abilities (within and out of the sample) of this new EWS compared to a wide range of alternative EWS (in particular the MS and the static logit models) are then investigated using the unified evaluation framework proposed by Candelon et al. (2009). Anticipating on our results, it turns out that the dynamic model including the lagged binary dependent variable outperforms (in-sample and out-of sample) most of the other specifications. Moreover, it appears the the new EWS has incredibly good outof-sample forecasting abilities when the forecast horizon increases. Considering a 24 month horizon, it identifies correctly almost all crisis and calm periods (more than $96 \%$ of the crisis periods and more than $98.2 \%$ of the calm ones) whatever the country and the type of analysis (time-series or panel). Finally, it turns out that the dynamic logit EWS outperforms its main competitors: the static logit and the MS.

This paper is structured as follows: the new estimation methods used for dynamic limited dependent EWS both in time-series and panel are presented in section 2. The database, the currency crisis dating methods as well as the estimation results are scrutinized in section 3. Section 4 proposes a comparison of the forecasting abilities of the models, while section 5 concludes.

\section{A Dynamic Specification of EWS}

In this section, the dynamic limited dependent EWS is presented both in its time-series and panel version. To date, almost all EWS models are static and do not exploit the persistence property of the crisis, captured by a lagged crisis index. This paper is the first one to consider a dynamic version of EWS based on an exact maximum likelihood estimation. Actually it was Kauppi and Saikkonen (2008) who showed that a maximum likelihood estimator $(\mathrm{ML})$ can be implemented under appropriate regularity conditions (stationarity of

explanatory variables and normality of the random variables), and it has desirable large sample properties. Moreover, within this framework it is possible to compare several dynamic alternatives: for example, Kauppi and Saikonnen (2008), show that a dynamic model including both the lagged value of the index and the one of the binary variable itself predicts U.S. recessions better than a static model. 


\subsection{Specification and Estimation}

Let us consider first the time-series version of the dynamic limited dependent EWS. We denote by $y_{n, t}, t \in\{1,2, \ldots, T\}$ the currency crisis binary variable for country $n$, taking the value of 1 if there will be at least a crisis in the following $j$ months and 0 if not and by $x_{n, t}$ the matrix of explanatory variables, whose first column is a unit vector. For ease of computation, hereafter $n$ will be omitted.

When using a logit model, the one-step-ahead dynamic specification accounting both for the influence of the lagged binary variable and that of the lagged index takes the form of: ${ }^{6}$

$$
\mathrm{P}_{t-1}\left(y_{t}=1\right)=\Lambda\left(\pi_{t}\right)=\Lambda\left(\alpha \pi_{t-1}+\delta y_{t-1}+x_{t-1} \beta\right),
$$

where $\mathrm{P}_{t-1}\left(y_{t}=1\right)$ is the conditional probability given the information set we have at our disposal at time $t-1$ and $\pi_{t}$ is the index at time $t$.

Actually, this is the first representation of Kauppi and Saikonnen (2008) applied to EWS models. The main advantage of this general framework is that it allows to estimate and then compare different alternative specifications. More precisely, we first consider the pure static model, in which the occurrence of currency crises is explained only by exogenous macroeconomic variables. Second, a dynamic model including the lagged value of the binary dependent variable $y_{t-1}$ is proposed. Third, a dynamic model including the lagged index $\pi_{t-1}$ is implemented. Finally, the most complex dynamic model, including both the lagged dependent variable $y_{t-1}$ and the lagged index $\pi_{t-1}$ is estimated. Given the maximum-likelihood framework, these dynamic time-series models are easy to implement using any existing econometric software. ${ }^{7}$ Besides, the ML estimators have the desired large-sample properties. In fact, the log-likelihood function takes the general form of:

$$
\log \mathrm{L}(\theta)=\sum_{t=1}^{T} l_{t}(\theta)=\sum_{t=1}^{T}\left[y_{t} \log \Lambda\left(\pi_{t}(\theta)\right)+\left(1-y_{t}\right) \log \left(1-\Lambda\left(\pi_{t}(\theta)\right)\right)\right],
$$

where $\theta$ is the vector of parameters.

Nevertheless, one should not loose sight of the fact that since in the last two models $\alpha$ is an autoregressive parameter, it has to satisfy the usual stationarity condition, i.e., the roots of the corresponding polynomial lie outside the unit circle. To tackle this problem, a constrained maximum likelihood estimation ${ }^{8}$ is implemented and described in Appendix 1.

6. It can be noted that the model for $h$-step-ahead forecasts can be obtained by repetitive substitutions. For more details, see Kauppi and Saikonnen (2008).

7. All the codes have been written in Matlab and are available from the authors upon request.

8. Besides, we tackle the autocorrelation problem induced by the construction of a $j$ months ahead crisis variable by considering a Gallant correction for the variance-covariance matrix. 


\subsection{Panel Data Analysis}

Instead of considering EWS for individual countries and hence applying a time-series approach, several papers (Berg and Patillo, 1998; Kumar et al., 2003) favor a panel data approach by pooling the information available in several countries. The main advantage of using panel data methods is the number of observations which increases the ability to estimate. Nevertheless, as shown by Berg et al. (2008), pooling all possible countries can be problematic for heterogenous countries. Thus, it is advisable to perform pre-cluster samples of countries. Here we present a dynamic version of a fixed effect panel model by elaborating on Carro (2007).

Let us consider here the panel version of the dynamic limited dependent EWS which has the following form:

$$
\mathrm{P}\left(y_{i t}=1\right)=\Lambda\left(\alpha y_{i t-1}+\beta x_{i t-1}+\eta_{i}\right), t=0,1,2, \ldots T, \text { and } i=1,2, . . N,
$$

where $N$ is the number of individuals in the panel, $T$ represents the number of time series observations for each individual, and $\eta_{i}$ accounts for the permanent unobserved heterogeneity between individuals. Since we do not impose any distributional assumption to $\eta_{i}, i=1,2, . . N$, they are treated as parameters to be estimated, and our approach is one with fixed effects. The dependent variable $y_{i t}$ equals 1 if if there will be at least a crisis in the following $j$ months and it equals 0 in the opposite case. Moreover, $x_{i t-1}$ represents the matrix of explicative variables, which can include besides macroeconomic variables the lagged index as well.

The log-likelihood of the model conditioned on the first observation, often called concentrated likelihood takes the following form:

$$
\operatorname{LogL}\left(\theta, \eta_{i}\right)=\sum_{i=1}^{N} \log \mathrm{L}_{i}\left(\theta, \eta_{i}\right)=\sum_{i=1}^{N} \sum_{t=1}^{T}\left[y_{i t} l n\left(\Lambda_{i t}\right)+\left(1-y_{i t}\right)\left(1-\Lambda_{i t}\right)\right],
$$

where $\theta=(\alpha, \beta)^{\prime}$. As usual, the estimated parameters maximize the log-likelihood function, which means that they solve the first order conditions with respect to $\theta$ and with respect to $\eta_{i}$. Most importantly, the estimation of $\theta$ depends on $\hat{\eta}_{i}$, which means that $\hat{\theta}$ is a convergent estimator of $\theta_{0}$ only when $\hat{\eta}_{i}$ is a convergent estimator of $\eta_{i 0}$, that is when $N \rightarrow \infty$. Thus, the central issue here, as in any non-linear panel model with fixed effects, is how to deal with this incidental parameters problem.

The solution proposed by Carro (2007) actually consists in a numerical substitution of the fixed effects $\left(\eta_{i}\right)$ in the estimation of $\theta$. Thus, at each step $N$ non-linear equations are solved so as to estimate $\hat{\eta}_{i}, i=1,2 \ldots N$ by using $\hat{\theta}$ obtained at the previous step and then the estimated values of $\hat{\eta}_{i}$ are introduced into the first order condition corresponding to the

concentrated likelihood so as to estimate $\hat{\theta}$. To be more precise, the estimation of $\eta$ is nested 
in the algorithm that maximizes the concentrated log-likelihood, so that at each iteration $N+1$ non-linear optimizations are realized using the Gauss-Newton algorithm (the first $N$ optimizations correspond to the fixed effects, while the last one corresponds to the $\theta$ parameters).

Moreover, in order to reduce the estimation bias from $O\left(T^{-1}\right)$ to $O\left(T^{-2}\right)$ without increasing the asymptotic variance, Carro proposed a modification of the first order condition expressed in terms of the original parameters of the model (hereafter MMLE). Consequently, the modified score for a certain country takes the following form:

$$
\begin{array}{r}
d_{\theta M i}(\theta)=d_{\theta C i}\left(\theta, \hat{\eta}_{i}(\theta)\right)-\frac{1}{2} \frac{1}{d_{\eta \eta i\left(\theta, \hat{\eta}_{i}(\theta)\right)}}\left(d_{\theta \eta \eta i\left(\theta, \hat{\eta}_{i}(\theta)\right)}+d_{\eta \eta \eta i\left(\theta, \hat{\eta}_{i}(\theta)\right)} \frac{\partial \hat{\eta}_{i}(\theta)}{\partial \theta}\right) \\
+\left.\frac{\partial / \partial \eta_{i}\left(E\left[d_{\theta \eta_{i}}\left(\theta, \eta_{i}\right) \mid y_{i 0}, \eta_{i}, x_{i}\right]\right)}{E\left[d_{\eta \eta_{i}}\left(\theta, \eta_{i}\right) \mid y_{i 0}, \eta_{i}, x_{i}\right]}\right|_{\eta_{i}=\hat{\eta}_{i}(\theta)}-\left.\frac{E\left[d_{\theta \eta_{i}}\left(\theta, \eta_{i}\right) \mid y_{i 0}, \eta_{i}, x_{i}\right]}{E\left[d_{\eta \eta_{i}}\left(\theta, \eta_{i}\right) \mid y_{i 0}, \eta_{i}, x_{i}\right]}\right|_{\eta_{i}=\hat{\eta}_{i}(\theta)} \\
\left.* \frac{\partial / \partial \eta_{i}\left(E\left[d_{\eta \eta_{i}}\left(\theta, \eta_{i}\right) \mid y_{i 0}, \eta_{i}, x_{i}\right]\right)}{E\left[d_{\eta \eta_{i}}\left(\theta, \eta_{i}\right) \mid y_{i 0}, \eta_{i}, x_{i}\right]}\right|_{\eta_{i}=\hat{\eta}_{i}(\theta)},
\end{array}
$$

where $d_{\theta C i}\left(\theta, \hat{\eta}_{i}(\theta)\right)$ is an individual's score from the concentrated likelihood (hereafter MLE):

$$
d_{\theta C i}\left(\theta, \hat{\eta}_{i}(\theta)\right)=\frac{y_{i t}-F_{i t}\left(\theta, \eta_{i}\right)}{F_{i t}\left(\theta, \eta_{i}\right)\left(1-F_{i t}\left(\theta, \eta_{i}\right)\right)}\left(y_{i t}+\frac{\partial \hat{\eta}_{i}(\theta)}{\partial \theta}\right) .
$$

The MMLE first order condition corresponding to the entire panel can be obtained by adding the individual MMLE scores.

At the same time, the corresponding standard errors can be easily obtained from the principal diagonal of the variance-covariance matrix, which is given by the inverse of the Hessian accounting for the fixed effects. The computation of the modified score and Hessian matrix is detailed in Appendix 2.

The main advantage of Carro's (2007) estimation method consists in its simplicity of implementation since it is based on the first derivatives of the log-likelihood function. At the same time, it allows for the estimation of all the dynamic specifications introduced in the previous subsection. Finally, given the reduction of the bias, the estimators have good asymptotic properties. ${ }^{9}$

\section{Empirical Application}

To compare the forecasting abilities of static and dynamic currency crises EWS, both time-series and panel models are estimated in order to retrieve the one-step ahead crisis

probabilities. Then, using the validation framework proposed by Candelon et al. (2009), the

9. All the codes have been developed in Matlab and are available upon request. 
best specification is selected and its forecasting performances are assessed : First, we proceed to an in-sample analysis using the entire database so as to identify the outperforming model. Second, aiming to assess the out-of-sample predictive abilities of the best model, we use a rolling windows procedure with a view to obtain out-of-sample forecasts.

Nevertheless, before starting the analysis per se, let us present some data-related issues.

\subsection{Data}

Monthly data expressed in US dollars covering the period 1985-2008 for 15 emerging countries ${ }^{10}$ have been extracted from the IMF-IFS database as well as the national banks of the countries under analysis via Datastream. Several explanatory variables from two economic sectors were selected (see Candelon et al. 2009, Berg et al., (2008), Lestano et al., 2003).

1. External sector: the one-year growth rate of international reserves, the one-year growth rate of imports, the one-year growth rate of exports, the ratio of M2 to foreign reserves, and the one-year growth rate of M2 to foreign reserves.

2. Financial sector: the one-year growth rate of M2 multiplier, the one-year growth rate of domestic credit over GDP, real interest rate and real exchange rate overvaluation.

As in Kumar (2003), we dampen every variable using the formula : $f\left(x_{t}\right)=\operatorname{sign}\left(x_{t}\right) *$ $\ln \left(1+\left|x_{t}\right|\right)$, so as to reduce the impact of extreme values. Traditional first generation (Im, Pesaran, Shin, 1997) as well as MW (Maddala and Wu 1999) and second generation (Bai and Ng, 2001 and Pesaran, 2003) panel unit root tests are performed, leading to the rejection of the null hypothesis of stochastic trend for all explanatory variables. Besides, the gaps through the series are replaced with the mean value of each series.

Since we aim to evaluate the forecasting abilities of dynamic logit models, we proceed to a general selection from the aforementioned exogenous variables, leading to the choice of only two macroeconomic variables. It is the first lag of these variables that is introduced into the models as a control variable, namely the one-year growth rate of international reserves and the one-year growth rate of M2 to foreign reserves. To be more exact, this selection is based on previous results found in the literature, on the correlation between the indicators, as well as on the explanatory power of each variable.

\subsection{Dating Currency Crises}

The most common method leading to the identification of currency crisis periods implies the computation of an index of speculative pressure. If this index exceeds a certain threshold,

10. Argentina, Brazil, Chile, Indonesia, Israel, Malaysia, Mexico, Morocco, Peru, Philippines, South Korea,Turkey, Thailand, Uruguay and Venezuela. 
a crisis episode is identified. As in Candelon et al. (2009), we base our choice on the results of Lestano and Jacobs (2004). Following their results, we identify crisis periods using the KLR modified pressure index (KLRm), which, unlike the KLR index, also includes interest rates:

$$
\operatorname{KLRm}_{n, t}=\frac{\Delta e_{n, t}}{e_{n, t}}-\frac{\sigma_{e}}{\sigma_{r}} \frac{\Delta r_{n, t}}{r_{n, t}}+\frac{\sigma_{e}}{\sigma_{i}} \Delta i_{n, t},
$$

where $e_{n, t}$ denotes the exchange rate (i.e., units of country $n$ 's currency per US dollar in period $t), r_{n, t}$ represents the foreign reserves of country $n$ in period $t$, while $i_{n, t}$ is the interest rate in country $n$ at time $t$. Meanwhile, the standard deviations $\sigma_{X}$ are actually the standard deviations of the relative changes in the variables $\sigma_{\left(\Delta X_{n, t} / X_{n, t}\right)}$, where $\mathrm{X}$ denotes each variable separately, including the exchange rate, foreign reserves, and the interest rate, with $\Delta X_{n, t}=$ $X_{n, t}-X_{n, t-6} \cdot{ }^{11}$ For both subsamples, the threshold equals two standard deviations above the mean: ${ }^{12}$

$$
\operatorname{Crisis}_{n, t}= \begin{cases}1, & \text { if } \mathrm{KLRm}_{n, t}>2 \sigma_{\mathrm{KLRm}_{n, t}}+\mu_{\mathrm{KLRm}_{n, t}} \\ 0, & \text { otherwise }\end{cases}
$$

\subsection{Optimal Country Clusters}

As Berg et al. (2008) have pointed out, pooling all available countries into one panel model might not be the best alternative especially in terms of forecasting abilities of the model. Nevertheless, a viable alternative to time-series estimation might be represented by a panel including only poolable countries. To be more precise, by poolable countries we mean a group of countries for which the slope parameters corresponding to the time-series models are statistically equal to the ones of a panel model including the same group of countries, i.e., $\beta_{i}=\beta_{p}$, where $\beta_{i}$ is the vector of parameters for country i and $\beta_{p}$ is the vector of parameters corresponding to the panel model. It is Kapetanios (2003) who proposed a sequential procedure based on an Hausman type statistic that tests the homogeneity of parameters between different countries grouped together in the same panel. Thus, it allows to isolate country clusters for which the null hypothesis of homogeneity of parameters cannot be rejected.

Following their recommendations, we apply the dynamic panel model on two optimal clusters (11 and respectively 2 countries out of 15) which are identified by using Kapetanios's methodology (Kapetanios, 2003). For the two non-poolable countries (Israel and South Korea) only time-series models are estimated.

11. Additionally, we take into account the existence of higher volatility in periods of high inflation, and consequently the sample is split into high and low inflation periods. The cut-off corresponds to a six month inflation rate higher than $50 \%$.

12. The variable Crisis corresponds to $y_{t}$ from our general framework. 


\subsection{Estimation Results}

In this subsection we first estimate different time-series models for each country and then, based on the Schwarz Information Criterion (hereafter SBC) we select the most parsimonious dynamic specification. Then, panel models corresponding to the best dynamic time-series model specification are estimated by using the whole sample of countries and respectively, by relying only on the poolable ones.

\section{insert Tables ??, ?? and ??}

Tables ??, ?? and ?? show the results of the ML estimates for the four time-series model specifications, i.e., the static model (Model 1), a dynamic one including the lagged binary dependent variable (Model 2), a dynamic one including the lagged index (Model 3), and last but not least, a dynamic model which includes both the lagged binary dependent variable and the lagged index (Model 4).

The goodness of fit indicator reveals that the independent variables have important explanatory power especially when the lagged dependent variable and/or the lagged index are present in the model, i.e., the dynamic models (see Table ??).

\section{insert Table ??}

More specifically, the lowest values of the SBC criterion are registered most of the time for these dynamic models and in particular for the second model, which seems to be the most adequate dynamic specification for most of the countries. ${ }^{13}$ To put it another way, the goodness of fit indicator is a clear indication of the fact that dynamic specifications generally outperform the static one. Nevertheless, a proper statistical assessment framework for the forecasting performance of static and dynamic models needs to be implemented, which is done in the next section.

At the same time, the signs of the estimated parameters in the best dynamic model, i.e., the second one, tend to correspond to a priori expectations. If an increase in a country's growth of international reserves indicator is observed at a certain moment in time, a decline in the probability of occurrence of currency crises is presumed, since it is perceived as an indicator of currency non-vulnerability, i.e., a negative coefficient of the growth of international reserves is awaited. Besides, the probability of currency-crisis emergence is supposed to escalate if an expansion of the growth of M2 to reserves is noticed in the previous period. To be more exact, if the growth of the amount of money in circulation overruns the growth of

13. Nevertheless, the third model seems better for countries like Brazil and Thailand, whereas the static model seems more parsimonious than the dynamic specifications for the countries registering a very small number of crisis periods (only one or two periods), countries for which no model can actually work well since we face a rare event data problem. 
international reserves, the currency is perceived as unstable and a speculative attack is foreseeable. Thus, a positive coefficient of the growth of M2 to reserves is expected. Nonetheless, several countries register strange signs, i.e. negative and significative coefficients.

To sum up, the coefficient of the lagged binary dependent variable is most of the time significant and has a positive sign (except for the countries for which the static model turns to perform better), whereas the impact of macroeconomic variables and of the lagged index

is different from one country to another (in terms of sign and significance), emphasizing the idea that accounting for the dynamics of the crisis is compulsory for the construction of a stringent EWS.

Since the second model appears to outperform the other dynamic specifications, we opt for the dynamic panel methodology in the form including the lagged binary dependent variable along with the selected macroeconomic indicators.

The results of the estimation of a dynamic panel logit model with fixed effects using the entire database and respectively using only the poolable countries are reported in Table ??. It can be noticed that the signs of the coefficients are similar from one model to another, and that most of them are significative for all the significance levels, i.e., $1 \%, 5 \%$ and $10 \%$. And yet, the coefficient of the growth of $M^{2}$ to reserves has the wrong sign for the panel including all the countries as well as for the first cluster of poolable countries, supporting the conclusion of Berg et al. (2008) that only poolable countries should be grouped together in a panel framework.

\section{Forecasts Evaluation}

So far we have seen that accounting for the currency crisis dynamics matters, and more exactly we have proved that the introduction of the lagged binary dependent variable into the model improves the estimation of currency crises probabilities. In this section we go one step further and statistically test the in-sample one-step-ahead forecasting abilities of the static and dynamic currency crisis EWS models by applying the validation methodology developed in Candelon et al. 2009. ${ }^{14}$ Then, the out-of-sample one-step ahead predictive abilities of the best model are checked. Finally, a robustness check is performed considering an horizon of 24 months for the out-of-sample forecast.

14. It consists in a 3-step approach: First, the optimal cut-off for each country based on an accuracy-error measures. Second, the predictive abilities of the two type of models is scrutinized. using criteria such as AUC, QPS, LPS, Kuiper's Score, Pietra Index and the Bayesian Error rate. Third, comparison tests are implemented so as to identify the outperforming model. To be more precise, a Clark-West test (Clark and West, 2007) is used in the case of nested models, while a Diebold-Mariano (Diebold and Mariano, 1995) test is utilized for non-nested models. 


\subsection{Time-series Models}

In this part of the paper, we check the within sample forecasting abilities of the static and dynamic time-series models. For this purpose, the whole dataset is considered (January 1986 - February 2008). Moreover, for comparability reasons, we gauge the forecasting abilities of dynamic Markov switching models. To this aim, a Markov-switching model is estimated for each country (see Abiad, 2003; Arias and Erlandson, 2005; Candelon et al. 2009). Nevertheless, contrary to the static model that has been previously used, our approach is based on a dynamic perspective, materialized in a switch of the lagged binary dependent variable from one regime to another, i.e., from crisis to calm periods and vice-versa. Once the filtered probabilities are computed, the model for each country is evaluated.

First of all, the optimal cut-offs as well as the percentage of correctly forecasted crises (sensitivity) and respectively calm periods (specificity) are available in Table ??.

\section{insert Table ??}

The optimal cut-off for each country has been identified by relying on the accuracy and error measures thus giving more weight to the correct identification of crises periods (sensitivity). Table ?? shows that both the static and dynamic country per country models are characterized by small values of the cut-offs (they range between 0.008 and 0.606). Moreover, both crisis and calm periods are very well forecasted by the dynamic logit model, i.e., sensitivity and specificity lay between $66.7 \%$ and $100 \%$ for each country while in the case of the static model they range between $50 \%$ and $100 \%$. This means that the lagged dependent variable has improved explanatory power and discriminates very well between calm and crisis periods.

Indeed, for most of the countries the crisis probabilities issued from the dynamic logit model are quite low during real calm periods and they are very high in the real crises periods (see Figure 1 and 2), reinforcing the idea that the dynamic model outperforms the static one. To be more precise, this model correctly forecasts most of the currency crisis episodes that been recorded and analyzed by other studies (Abiad, 1993; Dabrowski, 2003; Glick and Hutchison, 1999) as well as more recent ones, while the static model seems to be less efficient.

At the same time, the sensitivity and specificity of the dynamic Markov model vary a lot from one country to another, i.e. they sometimes reach their maximum, 1, but other times they drop to their minimum, 0, as well, indicating that dynamic Markov models may not be as good as the logit ones are. To confirm this intuition, a proper comparison test will be implemented further on.

Next, performance assessment criteria based on both sensitivity-specificity measures (AUC, Kuiper's score, Pietra index, Bayesian Error rate) and on the comparison of forecasts with the realizations of the crisis variable ( QPS and LPS) are used. We recall that 
the higher the value of AUC is the better the model will be; a positive value of Kuiper's score signifies that the model generates more hits than false alarms, and so its predictive performance should increase; similarly, a higher Pietra index, and a lower Bayesian error rate indicate a more stringent model, as do values of QPS and LPS closer to zero.

\section{insert Tables ?? and ??}

On the one hand, the results corresponding to the static time-series model are presented in the upper part of Table ??. By comparison with the results of the dynamic logit model (see the lower part of the Table ??), it seems that the values of the evaluation criteria of the static model are not as close to the optimum as for the dynamic model. The difference is most of the time at the second decimal, and it favors our dynamic specification.

On the other hand, the forecasting abilities of dynamic Markov models seem to vary a lot from one country to another (see Table ??); for example, QPS and LPS have relatively high values, while AUC is sometimes worst than the one of a random model. These findings support our intuition that the dynamic Markov model is not even as good as the static logit.

Finally, the optimal model specification is identified by applying Clark-West's MSPE-adj test and Diebold Mariano's DM test. First, the two time-series models are compared using Clark and West, (2007) test, suited to nested models, then, the test developed by DieboldMariano, (1995) is implemented so as to compare logit and Markov models. The results obtained are presented in Table ??.

\section{insert Table ??}

Table ?? reveals that the dynamic time-series specification outperforms the static one for most of the countries. ${ }^{15}$ Indeed, Clark-West's test rejects the null hypothesis of equal forecasting abilities for 10 out of the 15 countries. The results of these tests corroborate our main finding that the lagged binary dependent variable matters for the forecasting abilities of currency crises EWS models. Moreover, the middle part of Table ?? confirms the findings of Candelon et al. (2009) stressing the forecasting superiority of the logit models versus the dynamic Markov models.

\subsection{Panel Models}

So far, we have shown that time-series dynamic logit models outperform both static logit models and dynamic Markov switching specifications. Now, the two dynamic panel models considered in the paper (based on all available countries and respectively using only the

15. As we have already seen in the information criterion Table, that there are several countries for which the static model seems better than the dynamic. Here we have the statistical proof that for Brazil, Chile, Israel, South Korea and Morocco the static and dynamic models have similar forecasting abilities. 
poolable ones) are evaluated and their in sample forecasting abilities compared to those of the best time-series specification, i.e., the dynamic logit model including the lagged binary dependent variable.

\section{insert Table ??}

First of all, in the case of the dynamic panel models the values of the optimal cut-off are similar to the ones registered for the dynamic time-series logit models, even though fairly smaller i.e., they vary between 0.001 and 0.74 (see Table ??). Similarly, sensitivity and specificity values corresponding to the two types of dynamic models resemble. All in all, the results obtained by using a panel model do not seem to diverge much from those obtained when using time-series models. To check this intuition, proper statistical comparison tests are applied at the end of this section.

\section{insert Table ??}

Second, Table ?? shows that the dynamic panel models generally have good forecasting abilities. To be more precise, with the exception of Chile, Morocco and Uruguay, the AUC is always greater than 0.8 , Kuiper's score has positive values, Pietra index registers relatively high values, while the Bayesian Error rate, QPS and LPS are very close to 0 (inferior to 0.153 to be more exact). Besides, the results are very similar from one dynamic model to another except for Uruguay, for which the results cluster estimation are worst than the ones corresponding to the entire dataset.

Last but not least, the two dynamic panel models are compared to the time-series dynamic one and to the dynamic Markov-switching specification by using the DM test proposed by Diebold-Mariano (1995).

\section{insert Table ??}

Table ?? shows that the null hypothesis of equal forecasting abilities cannot be rejected, thus clarifying the fact that the dynamic panel models do not have better forecasting abilities than the dynamic time series one, supporting the results obtained by Berg et al (2008). The only exceptions are Marocco and Venezuela. Besides, the right part of Table ?? proves that not only time-series dynamic logit models but also dynamic panel logit models are better than dynamic Markov-switching specifications.

\subsection{Out-of-sample analysis}

In the previous subsections the properties of the dynamic logit model including the lagged binary dependent variable have been investigated. Nevertheless, the out-of-sample characteristics of such an EWS model have to be checked before concluding. 
To this aim, an out-of-sample experiment using a rolling windows procedure has been implemented. More precisely, in order to compute the probability of having a crisis in January 1997, a dynamic time-series logit model is estimated using the dataset from January 1986 to December 1996 and the parameters obtained are used to calculate the crisis probability for January 1997. Similarly, for February 1997, the in-sample data corresponds to the February 1986-January 1997 period, and so on. A series of out-of-sample crisis probabilities is thus obtained for each country so that the aforementioned evaluation methodology can be applied straightforward.

Figure 3 presents the out-of-sample crisis probabilities from January 1997 to February 2008 for each of the 11 countries registering at least one crisis for the in-sample period (January 1986 - December 1996). ${ }^{16}$ It appears that for the countries which faced more than one month of currency crisis, the EWS forecasting probability is very low in calm periods while it is very high during crisis periods. It hence follows closely the in-sample results. On the contrary, when countries faced only one period of crisis, forecasting abilities are disappointing. Such a result is driven by the low amount of crisis observations : the number of 0 is huge, hence causing bias in the estimation of the dynamic logit model. Thus, this findings would support the use of longer forecast horizons as it is usually done in the literature. Considering a forecast horizon of $j$ months increases "artificially" the number of 1 observation in the sample, which improves the quality of the estimation and hence of the forecasting ability. Nevertheless, it also introduced autocorrelation (see Berg and Coke, 2004) which may be problematic.

Consequently, a robustness check is performed by employing the $C 24$ crisis variable. Figures 4 and 5 present the out-of-sample probabilities corresponding to this new binary variable. This time the results are excellent, since the crisis probability is very high in real crisis periods while it is very low in real calm periods. Even for the countries which never faced a crisis the results are quite spectacular since the crisis probability is always low. Indonesia and Thailand are the only exceptions, for which a high probability pick can be observed in a calm period. Nevertheless, the picks are not persistent and thus, they can hardly be perceived as signals of crisis. Besides, results are available for all countries, since, contrary to the previous case, they all face currency crises in the within-sample period.

To summarize, it seems that all the EWS considering a forecast horizon $j$, where $j>1$ should be dynamic, since the autocorrelation can be successfully captured improving hence the forecasting abilities of the EWS model.

The cutoffs used for the out-of-sample series of crisis probabilities in both cases (crisis at time $t$ and respectively in 24 months) are reported in Table ??, while the out-of-sample validation results are displayed in Table ??. The superiority of the forecasting results corres-

16. If there is not any in-sample crisis, we cannot compute the optimal cut-off needed in order to evaluate the out-of-sample forecasting abilities of the model. 
ponding to the $\mathrm{C} 24$ variable is clear. Sensitivity and specificity are always higher than the ones corresponding to the crisis at time $t$ variable. Similarly, AUC, Kuiper's score, Pietra index and Bayesian error rate are higher while QPS and LPS are lower for C24.

insert Tables ?? and ??

\section{Conclusion}

This paper provides evidence of the importance of crisis dynamics to adequately forecast crises and shows that future EWS models should integrate this dynamic. It is actually the first to consider an exact ML methodology, elaborated on Kauppi and Saikonnen (2008), to estimate a dynamic limited dependent EWS. In a second part, it extends this methodology to panel by drawing on the works of Carro (2007).

Several conclusions can be drawn from the empirical application of this methodology to construct currency crisis EWS models. First, we show that dynamic logit models consistently outperform static ones as well as MS. This conclusion is drawn from the within sample forecast exercise. Such a result is corroborated by the out-of-sample forecast exercise performed by considering an horizon larger than 1 . This can be explained by the fact that dynamic captures the autocorrelation observe in such EWS. Second, looking at their forecasting ability, it turns out that dynamic EWS deliver extremely good forecasting probabilities: close to 1 in the crisis periods or and near 0 the rest of the time.

There is no doubt that in the quest for a new generation for financial crisis EWS, dynamics should constitute a key characteristic that would deliver more adequate signals to prevent financial turmoils. Let us hope that policy makers could exploit these signals to tame such painful events. 


\section{Bibliography}

1. Abiad, A., (2003). Early Warning systems: A Survey and a Regime Switching Approach, IMF Working Paper.

2. Arias, G. and Erlandsson, G., (2005). Improving Early Warning Systems with a Markov Switching Model - an Application to South-East Asian Crises, Lund University, Working Paper.

3. Bai, J., and Ng,S., (2001). A New Look at Panel Testing of Stationarity and the PPP Hypothesis, Boston College Working Papers in Economics 518, Boston College Department of Economics.

4. Basel Committee on Banking Supervision, (2005). Studies on the Validation of Internal Rating Systems, working paper no.14, Bank for International Settlements.

5. Berg, A., and Pattillo, C., (1999). Predicting Currency Crises: The Indicators Approach and an Alternative. Journal of International Money and Finance, 18, 561-586.

6. Berg, J.B., Candelon, B, and Urbain, J.P., (2008). A Cautious Note on the Use of Panel Models to Predict Financial Crises, Economics Letters 101, issue 1, 80-83.

7. Berg, A., and Cooke, R., (2004). Autocorrelation Corrected Standard Errors in Panel Probits: an Application to Currency Crisis Prediction, IMF Working Paper.

8. Bussiere, M. and Fratzscher, M., (2006). Towards a New Early Warning System of Financial Crises, Journal of International Money and Finance, 25(6), 953-973.

9. Candelon, B., Dumitrescu, E.I., Hurlin, C., (2009). How to evaluate an Early Warning System? Towards a Unified Statistical Framework for Assessing Financial Crises Forecasting Methods, Working Paper.

10. Carro, J.M., (2007). Estimation dynamic panel data discrete choice models with fixed effects, Journal of Econometrics, 140, 503-528.

11. Clark, T. E., West, K. D., (2007). Approximately Normal Tests for Equal Predictive Accuracy in Nested Models, Journal of Econometrics, 138(1), 291-311.

12. Dabrowski, M. and Jakubiak, M., (2003). The Sources of Economic Growth in Ukraine after 1998 Currency Crisis and the Country's Prospects, CASE Network Reports 0055, CASE-Center for Social and Economic Research.

13. Diebold, F. X., Mariano, S., (1995). Comparing Predictive Accuracy, Journal of Business and Economic Statistics, American Statistical Association, 13(3), 253-63.

14. Falcetti, E., Tudela, M., (2006). Modelling Currency Crises in Emerging Markets: A Dynamic Probit Model with Unobserved Heterogeneity and Autocorrelated Errors, Oxford Bulletin of Economics and Statistics, 68(4), pages 445-471. 
15. Gallant, A. R., (1987). Nonlinear Statistical Models, John Wiley and Sons, New York.

16. Fratzscher,M., (2003). On Currency Crises and Contagion, International Journal of Finance and Economics, 8(2), 109-129.

17. Fuertes, A.-M., Kalotychou, E., (2007) Optimal Design of Early Warning Systems for Sovereign Debt Crises, International Journal of Forecasting, 23(1), 85-100.

18. Glick, R. and Hutchison, M., (1999). Banking and Currency Crises : How Common Are The Twins?, Working Papers 012000, Hong Kong Institute for Monetary Research.

19. Im, K.S. \& Pesaran, M. H., \& Shin, Y., (2003). Testing for Unit Roots in Heterogeneous Panels, Journal of Econometrics, 115(1), 53-74.

20. Kaminsky, G., Lizondo, S., Reinhart, C., (1998). Leading Indicators of Currency Crises, IMF Staff Papers, 45(1), 1-48.

21. Kapetanios, G., (2003). Determining the Poolability of Individual Series in Panel Datasets, Working Paper 499.

22. Kauppi, H., Saikkonen, P., (2008), Predicting U.S. Recessions with Dynamic Binary Response Models, The Review of Economics and Statistics, 90(4), 777-791.

23. Kumar, M., Moorthy, U. and Perraudin, W., (2003). Predicting Emerging Market Currency Crashes, Journal of Empirical Finance, 10, 427-454.

24. Lambert, J. and Lipkovich, I., (2008). A Macro for Getting more out of your ROC Curve, SAS Global forum, paper 231.

25. Lestano and Jacobs, J., (2004). A Comparison of Currency Crisis Dating Methods: East Asia 1970-2002, CCSO Working Papers 200412, CCSO Centre for Economic Research.

26. Maddala, G.S., and Wu, S., (1999). A Comparative Study of Unit Root Tests with Panel Data and a New Simple Test, Oxford Bulletin of Economics and Statistics, special issue, 631-652.

27. Martinez Peria, M.S., (2002). A regime-switching approach to the study of speculative attacks: A focus on EMS crises, Empirical Economics, 27(2), 299-334.

28. Pesaran, H., (2007). A Simple Panel Unit Root Test in the Presence of Cross-Section Dependence, Journal of Applied Econometrics, 22(2), pages 265-312.

29. Rose, A.K. and Spiegel, M.M., (2010). Cross-Country Causes and Consequences of the 2008 Crisis: Early Warning, forthcoming in Pacific Economic Review.

30. Tudela, M., (2004). Explaining Currency Crises: a Duration Model Approach, Journal of International Money and Finance, 23(5), 799-816. 


\section{Appendix 1: Constrained Maximum Likelihood Estima- tion (Kauppi and Saikkonen, 2008)}

Let us recall the general form of the model: $\mathrm{P}_{t-1}\left(y_{t}=1\right)=\Lambda\left(\alpha \pi_{t-1}+\delta y_{t-1}+x_{t-1} \beta\right)$. Following Kauppi and Saikkonen, we set the initial value $\pi_{0}$ to $(\bar{x} \beta) /(1-\alpha), \bar{x}$ being the sample mean of the exogenous variables. The initial condition for the $\beta$ vector of parameters is given by an OLS estimation, while the initial $\alpha$ is set to 0 . Moreover, since $\alpha$ is an autoregressive parameter, a constrained maximum likelihood estimation must be implemented. Nevertheless, the same results can be reached in a faster and easier way, by using a transformation of the $\alpha$ parameter in the classical maximum likelihood process. Thus, to solve this problem, we denote by $\psi$ the new maximization parameter, identified so that $\alpha$ is equal to $\psi /(1+|\psi|)$, i.e., $\alpha$ takes values in the interval $[0,1]$.

Hence, the log-likelihood function takes the form of:

$$
\log L(\theta)=\sum_{t=1}^{T} l_{t}(\theta)=\sum_{t=1}^{T}\left[y_{t} \log \Lambda\left(\pi_{t}(\theta)\right)+\left(1-y_{t}\right) \log \left(1-\Lambda\left(\pi_{t}(\theta)\right)\right)\right]
$$

where $\theta$ is the vector of parameters $\theta=[\psi \beta]$.

It is noticed that in view of the parameter transformation from $\alpha$ to $\psi$, the maximization variance-covariance matrix corresponds to the parameters $[\beta \psi]$, and not to the initial parameters $\left[\begin{array}{ll}\beta & \alpha\end{array}\right]$. Thus, we must proceed to a change of the variance-covariance matrix from the first space to the second one. To this end, we use Taylor's theorem to calculate the approximation of the transformation function around the point $\psi_{0}$. To be more exact, since the estimated parameter $\hat{\alpha}=f(\hat{\psi})$, where $f(\hat{\psi})=\hat{\psi} /(1+|\hat{\psi}|)$, the approximation becomes:

$$
\hat{\alpha}=f(\hat{\psi}) \simeq f\left(\psi_{0}\right)+\left.\frac{\partial f(\hat{\psi})^{\prime}}{\partial \psi}\right|_{\psi_{0}}\left(\hat{\psi}-\psi_{0}\right)
$$

Nevertheless, we aim at finding the variance of $\alpha$, and thus, using the formula $\operatorname{Var}\left(a^{\prime} X\right)=$ $a^{\prime} \operatorname{Var}(X) a$, we obtain:

$$
\operatorname{Var}(\hat{\alpha}) \simeq 0+\left.\left.\frac{\partial f(\hat{\psi})^{\prime}}{\partial \psi}\right|_{\psi_{0}} \operatorname{Var}(\hat{\psi}) \frac{\partial f(\hat{\psi})}{\partial \psi}\right|_{\psi_{0}}
$$

Since $\hat{\psi} \stackrel{p}{\rightarrow} \psi_{0}$, we can replace $\psi_{0}$ with the estimator $\hat{\psi}$ in eq. 8:

$$
s \operatorname{Var}(\hat{\alpha}) \simeq 0+\left.\left.\frac{\partial f(\hat{\psi})^{\prime}}{\partial \psi}\right|_{\hat{\psi}} \operatorname{Var}(\hat{\psi}) \frac{\partial f(\hat{\psi})}{\partial \psi}\right|_{\hat{\psi}}
$$

Last but not least, the first derivative of the transformation function $f(\hat{\psi})$ with respect to $(\hat{\psi})$ 
can be computed through finite differences. Consequently, the standard errors obtained as the square root of the elements laying on the first diagonal of the variance-covariance matrix are consistent with the $[\alpha \psi]$ vector of parameters. More exactly, a Gallant correction based on a Parzen kernel (Gallant, 1987) is used for the variance-covariance matrix. Kauppi and Saikonnen (2008) argue that robust standard errors can be obtained as the diagonal elements of the matrix $\hat{J}(\hat{\theta})^{-1} \hat{I}(\hat{\theta}) \hat{J}(\hat{\theta})^{-1}$, where $\hat{I}(\hat{\theta})=T^{-1}\left(\sum_{t=1}^{T} \hat{d}_{t}^{\prime} \hat{d}_{t}+\sum_{t=1}^{T} w_{T j} \sum_{t=j+1}^{T}\left(\hat{d}_{t}^{\prime} \hat{d}_{t-j}+\right.\right.$ $\left.\left.\hat{d}_{t-j}^{\prime} \hat{d}_{t}\right)\right), \hat{d}_{t}=\partial l_{t}(\hat{\theta}) \partial \theta$, and where $J(\theta)=p \lim _{T \rightarrow \infty} T^{-1} \sum_{t=1}^{T}\left(\partial^{2} l_{t}(\theta) \partial \theta \partial \theta^{\prime}\right)$. On top of that, we consider that the robust variance-covariance matrix should be used not only for $h$-periodsahead forecasts, $h>1$ (as in Kauppi and Saikonnen, 2008) but also for one period-ahead forecasts, since the logistic distributional hypothesis imposed to the error term might not always hold and most importantly, since this variance-covariance matrix specification is robust to autocorrelation, automatically introduced when considering an EWS (see Berg and Coke, 2004).

\section{Appendix 2: Modified Maximum Likelihood Estimation (Carro, 2007)}

As previously mentioned, the dynamic panel logit models with fixed effects is estimated by solving $N+1$ non-linear equations based on the modified score of each individual, which takes the following form:

$$
\begin{array}{r}
d_{\theta M i}(\theta)=d_{\theta C i}\left(\theta, \hat{\eta}_{i}(\theta)\right)-\frac{1}{2} \frac{1}{d_{\eta \eta i\left(\theta, \hat{\eta}_{i}(\theta)\right)}}\left(d_{\theta \eta \eta i\left(\theta, \hat{\eta}_{i}(\theta)\right)}+d_{\eta \eta \eta i\left(\theta, \hat{\eta}_{i}(\theta)\right)} \frac{\partial \hat{\eta}_{i}(\theta)}{\partial \theta}\right) \\
+\left.\frac{\partial / \partial \eta_{i}\left(E\left[d_{\theta \eta_{i}}\left(\theta, \eta_{i}\right) \mid y_{i 0}, \eta_{i}, x_{i}\right]\right)}{E\left[d_{\eta \eta_{i}}\left(\theta, \eta_{i}\right) \mid y_{i 0}, \eta_{i}, x_{i}\right]}\right|_{\eta_{i}=\hat{\eta}_{i}(\theta)}-\left.\frac{E\left[d_{\theta \eta_{i}}\left(\theta, \eta_{i}\right) \mid y_{i 0}, \eta_{i}, x_{i}\right]}{E\left[d_{\eta \eta_{i}}\left(\theta, \eta_{i}\right) \mid y_{i 0}, \eta_{i}, x_{i}\right]}\right|_{\eta_{i}=\hat{\eta}_{i}(\theta)} \\
\left.* \frac{\partial / \partial \eta_{i}\left(E\left[d_{\eta \eta_{i}}\left(\theta, \eta_{i}\right) \mid y_{i 0}, \eta_{i}, x_{i}\right]\right)}{E\left[d_{\eta \eta_{i}}\left(\theta, \eta_{i}\right) \mid y_{i 0}, \eta_{i}, x_{i}\right]}\right|_{\eta_{i}=\hat{\eta}_{i}(\theta)},
\end{array}
$$

where $d_{\theta C i}\left(\theta, \hat{\eta}_{i}(\theta)\right)$ is an individual's score from the concentrated likelihood (MLE):

$$
d_{\theta C i}\left(\theta, \hat{\eta}_{i}(\theta)\right)=\frac{y_{i t}-F_{i t}\left(\theta, \eta_{i}\right)}{F_{i t}\left(\theta, \eta_{i}\right)\left(1-F_{i t}\left(\theta, \eta_{i}\right)\right)}\left(y_{i t}+\frac{\partial \hat{\eta}_{i}(\theta)}{\partial \theta}\right)
$$

From the first order condition of $\eta_{i}, d_{\eta_{i}}\left(\theta, \eta_{i}\right)=\sum_{t=1}^{T}\left(y_{i t}-F_{i t}\left(\theta, \eta_{i}\right)\right) / F_{i t}\left(\theta, \eta_{i}\right)\left(1-F_{i t}\left(\theta, \eta_{i}\right)\right)=$ 0 , it can be derived that the estimators $\hat{\eta}_{i}, i=1,2, \ldots, N$ solve the following equation:

$$
\sum_{t=1}^{T} y_{i t} \frac{f_{i t}\left(\theta, \eta_{i}\right)}{F_{i t}\left(\theta, \eta_{i}\right)\left(1-F_{i t}\left(\theta, \eta_{i}\right)\right)}=\sum_{t=1}^{T} \frac{F_{i t}\left(\theta, \eta_{i}\right) f_{i t}\left(\theta, \eta_{i}\right)}{F_{i t}\left(\theta, \eta_{i}\right)\left(1-F_{i t}\left(\theta, \eta_{i}\right)\right)}
$$


Deriving Equation (15) with respect to $\theta$ we can obtain $\partial \hat{\eta}_{i}(\theta) / \partial \theta$ :

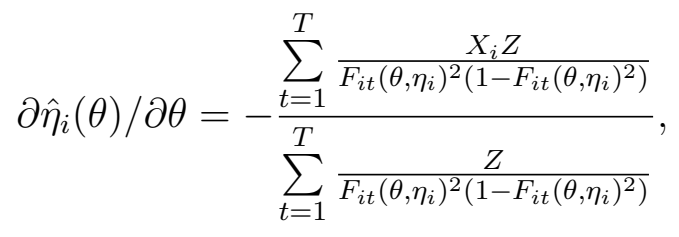

where $X_{i}=y_{t-1}, x_{i 1}, x_{i 2}, \ldots, x_{i K}$, is the explanatory variable corresponding to the $\theta=$ $\alpha, \beta_{1}, \beta_{2}, \ldots, \beta_{K}$ parameter we analyze, $\mathrm{K}$ is the number of explanatory variables, and $Z=$ $y_{t}\left[f_{i t}^{\prime}\left(\theta, \eta_{i}\right) F_{i t}\left(\theta, \eta_{i}\right)\left(1-F_{i t}\left(\theta, \eta_{i}\right)\right)-f_{i t}^{2}\left(\theta, \eta_{i}\right)\left(1-2 F_{i t}\left(\theta, \eta_{i}\right)\right)\right]-f_{i t}^{2}\left(\theta, \eta_{i}\right) F_{i t}^{2}\left(\theta, \eta_{i}\right)-F_{i t}^{2}\left(\theta, \eta_{i}\right)(1-$ $\left.F_{i t}\left(\theta, \eta_{i}\right)\right) f_{i t}^{\prime}\left(\theta, \eta_{i}\right)$. Let us remind that $F_{i t}\left(\theta, \eta_{i}\right)$ is the cumulative distribution function, $f_{i t}\left(\theta, \eta_{i}\right)$ is the density function and $f_{i t}^{\prime}\left(\theta, \eta_{i}\right)$ is the first derivative of the density function. Thus, in the case of a logit model $F_{i t}\left(\theta, \eta_{i}\right)=\exp \left(\alpha y_{i t-1}+x_{i t-1} \beta+\eta_{i}\right) /\left(1+\exp \left(\alpha y_{i t-1}+\right.\right.$ $\left.\left.x_{i t-1} \beta+\eta_{i}\right)\right), f_{i t}\left(\beta, \eta_{i}\right)=\exp \left(\alpha y_{i t-1}+x_{i t-1} \beta+\eta_{i}\right) /\left(1+\exp \left(\alpha y_{i t-1}+x_{i t-1} \beta+\eta_{i}\right)\right)^{2}$, and $f_{i t}^{\prime}\left(\beta, \eta_{i}\right)=\exp \left(\alpha y_{i t-1}+x_{i t-1} \beta+\eta_{i}\right)\left(1-\exp \left(\alpha y_{i t-1}+x_{i t-1} \beta+\eta_{i}\right)\right) /\left(1+\exp \left(\alpha y_{i t-1}+x_{i t-1} \beta+\right.\right.$ $\left.\left.\eta_{i}\right)\right)^{3}$.

To put it another way, the partial derivative of the $\eta$ gradient with respect to $\theta$ is given by the implicit functions theorem:

$$
\partial \hat{\eta}_{i}(\theta) / \partial \theta_{k}=-\frac{\partial d_{\eta_{i}}\left(\theta, \hat{\eta}_{i}\right) / \partial \theta_{k}}{\partial d_{\eta_{i}}\left(\theta, \hat{\eta}_{i}\right) / \partial \eta_{i}},
$$

where $\mathrm{k}=1,2, \ldots \mathrm{K}, \mathrm{K}$ being the number of explanatory variables considered in the model, $\partial d_{\eta_{i}}\left(\theta, \hat{\eta}_{i}\right) / \partial \theta_{k}=\partial^{2} \log \mathrm{L}\left(\theta, \eta_{i}\right) / \partial \eta_{i} \partial \theta_{k} \mid\left(\theta, \hat{\eta}_{i}\right)$, and $\partial d_{\eta_{i}}\left(\theta, \hat{\eta}_{i}\right) / \partial \eta_{i}=\partial^{2} \log \mathrm{L}\left(\theta, \eta_{i}\right) / \partial^{2} \eta_{i} \mid\left(\theta, \hat{\eta}_{i}\right)$. The estimation of the parameters by classical MLE is straightforward since $d_{\theta C i}\left(\theta, \hat{\eta}_{i}(\theta)\right)=0$ and $d_{\eta_{i}}\left(\theta, \eta_{i}\right)=0$ can be easily computed and solved. However, aiming to reduce the estimation bias, the implementation of MMLE becomes compulsory, for which further information regarding the expectance of the first order condition and the derivatives of this expectance is required.

In view of the MMLE estimation, we derive the following elements for the $\alpha$ parameter, corresponding to the lagged binary variable:

$$
\begin{aligned}
& d_{\alpha \eta_{i}}\left(\theta, \eta_{i}\right)=\frac{\partial^{2} \log \mathrm{L}_{i}}{\partial \alpha \partial \eta_{i}}=-\sum_{t=1}^{T} y_{i, t-1} f_{i t}\left(\alpha y_{i t-1}+\beta x_{i}+\eta_{i}\right), \\
& d_{\eta_{i} \eta_{i}}\left(\theta, \eta_{i}\right)=\frac{\partial^{2} \log \mathrm{L}_{i}}{\partial^{2} \eta_{i}}=-\sum_{t=1}^{T} f_{i t}\left(\alpha y_{i t-1}+\beta x_{i}+\eta_{i}\right)
\end{aligned}
$$




$$
\begin{aligned}
& d_{\alpha \eta_{i} \eta_{i}}\left(\theta, \eta_{i}\right)=-\sum_{t=1}^{T} y_{i, t-1} f_{i t}^{\prime}\left(\alpha y_{i t-1}+\beta x_{i}+\eta_{i}\right), \\
& d_{\eta_{i} \eta_{i} \eta_{i}}\left(\theta, \eta_{i}\right)=-\sum_{t=1}^{T} f_{i t}^{\prime}\left(\alpha y_{i t-1}+\beta x_{i}+\eta_{i}\right)
\end{aligned}
$$

where $f$ is the logistic pdf and $f^{\prime}$ is the first derivative of the logistic pdf.

Next, we aim at calculating the expectation of the derivatives $d_{\alpha \eta_{i}}$ and $d_{\eta_{i} \eta_{i}}$. Thus, in a first step we calculate the probability at time $t$ that a crisis will occur in country $i$ in the next 24 months given the initial value of the binary dependent variable $y_{i 0}$, the fixed effects $\eta_{i}$ and the explanatory variables $x_{i}\left(\operatorname{Pr}\left(y_{i t}=1 \mid y_{i 0}, \eta_{i}, x_{i}\right)\right)$ :

$\operatorname{Pr}\left(y_{i 1}=1 \mid y_{i 0}, \eta_{i}, x_{i}\right)=F_{i t}\left(\alpha y_{i 0}+\beta x_{i}+\eta_{i}\right)$ starting point. For $t>1:$

$\operatorname{Pr}\left(y_{i t}=1 \mid y_{i 0}, \eta_{i}, x_{i}\right)=\operatorname{Pr}\left(y_{i t-1}=1 \mid y_{i 0}, \eta_{i}, x_{i}\right)\left(F_{i t}\left(\alpha+\beta x_{i}+\eta_{i}\right)-F_{i t}\left(\beta x_{i}+\eta_{i}\right)\right)+F_{i t}\left(\beta x_{i}+\eta_{i}\right)$.

Moreover, $\operatorname{Pr}\left(y_{i 0}=1 \mid y_{i 0}, \eta_{i}, x_{i}\right)=y_{i 0}$.

In the second step the expectation of the two derivatives can be calculated:

$$
\begin{aligned}
& E\left[d_{\alpha \eta_{i}}\left(\theta, \eta_{i}\right) \mid y_{i 0}, \eta_{i}, x_{i}\right]=-\sum_{t=1}^{T} E\left[y_{i t-1} f_{i t}\left(\alpha y_{i t-1}+\beta x_{i}+\eta_{i}\right) \mid y_{i 0}, \eta_{i}, x_{i}\right], \text { where } \\
& E\left[y_{i t-1} f_{i t}\left(\alpha y_{i t-1}+\beta x_{i}+\eta_{i}\right) \mid y_{i 0}, \eta_{i}, x_{i}\right]=f_{i t}\left(\alpha+\beta x_{i}+\eta_{i}\right) \operatorname{Pr}\left(y_{i t-1}=1 \mid y_{i 0}, \eta_{i}, x_{i}\right) .
\end{aligned}
$$

and

$$
\begin{aligned}
E\left[d_{\eta_{i} \eta_{i}}\left(\theta, \eta_{i}\right) \mid y_{i 0}, \eta_{i}, x_{i}\right]=-\sum_{t=1}^{T} E[ & \left.f_{i t}\left(\alpha y_{i t-1}+\beta x_{i}+\eta_{i}\right) \mid y_{i 0}, \eta_{i}, x_{i}\right], \text { where } \\
E\left[f_{i t}\left(\alpha y_{i t-1}+\beta x_{i}+\eta_{i}\right) \mid y_{i 0}, \eta_{i}, x_{i}\right] & =f_{i t}\left(\alpha+\beta x_{i}+\eta_{i}\right) \operatorname{Pr}\left(y_{i t-1}=1 \mid y_{i 0}, \eta_{i}, x_{i}\right) \\
& +f_{i t}\left(\beta x_{i}+\eta_{i}\right)\left(1-\operatorname{Pr}\left(y_{i t-1}=1 \mid y_{i 0}, \eta_{i}, x_{i}\right)\right) \\
& =\operatorname{Pr}\left(y_{i t-1}=1 \mid y_{i 0}, \eta_{i}, x_{i}\right)\left(f_{i t}\left(\alpha+\beta x_{i}+\eta_{i}\right)\right. \\
& \left.-f_{i t}\left(\beta x_{i}+\eta_{i}\right)\right)+f_{i t}\left(\beta x_{i}+\eta_{i}\right)
\end{aligned}
$$

The last elements needed in the gradient function are the derivatives of the two expectations of $d_{\alpha \eta_{i}}$ and $d_{\eta_{i} \eta_{i}}$ with respect to the fixed effect $\eta_{i}$. Nevertheless, to compute these elements, the derivative of the probability of occurrence of a crisis within 24 months at time $t$ in 
country $i$ with respect to $\eta_{i}$ must be first calculated:

$$
\begin{aligned}
\frac{\partial}{\partial \eta_{i}} \operatorname{Pr}\left(y_{i 1}=1 \mid y_{i 0}, \eta_{i}, x_{i}\right) & =f_{i 1}\left(\alpha y_{i 0}+\beta x_{i}+\eta_{i}\right) \\
\frac{\partial}{\partial \eta_{i}} \operatorname{Pr}\left(y_{i t}=1 \mid y_{i 0}, \eta_{i}, x_{i}\right) & =\frac{\partial}{\partial \eta_{i}} \operatorname{Pr}\left(y_{i t-1}=1 \mid y_{i 0}, \eta_{i}, x_{i}\right)\left(F_{i t}\left(\alpha+\beta x_{i}+\eta_{i}\right)-F_{i t}\left(\beta x_{i}+\eta_{i}\right)\right) \\
& +\operatorname{Pr}\left(y_{i t}=1 \mid y_{i 0}, \eta_{i}, x_{i}\right)\left(f_{i t}\left(\alpha+\beta x_{i}+\eta_{i}\right)-f_{i t}\left(\beta x_{i}+\eta_{i}\right)\right)+f_{i t}\left(\beta x_{i}+\eta_{i}\right)
\end{aligned}
$$

Finally, the last elements needed in the formula of the gradient are obtained

$$
\begin{aligned}
\frac{\partial}{\partial \eta_{i}}\left(E\left[d_{\alpha \eta_{i}}\left(\theta, \eta_{i}\right) \mid y_{i 0}, \eta_{i}, x_{i}\right]\right) & =-\sum_{t=1}^{T} \frac{\partial}{\partial \eta_{i}} E\left[y_{i t-1} f\left(\alpha y_{i t-1}+\beta x_{i t-1}+\eta_{i}\right) \mid y_{0}, \eta_{i}, x_{i}\right] \\
& =f^{\prime}\left(\alpha+\beta x_{i t-1}+\eta_{i}\right) \operatorname{Pr}\left(y_{i t-1}=1 \mid y_{i 0}, \eta_{i}, x_{i}\right) \\
& +f\left(\alpha+\beta x_{i t-1}+\eta_{i}\right) \frac{\partial}{\partial \eta_{i}} \operatorname{Pr}\left(y_{i t-1}=1 \mid y_{i 0}, \eta_{i}, x_{i}\right)
\end{aligned}
$$

and respectively

$$
\begin{aligned}
\frac{\partial}{\partial \eta_{i}}\left(E\left[d_{\eta_{i} \eta_{i}}\left(\theta, \eta_{i}\right) \mid y_{i 0}, \eta_{i}, x_{i}\right]\right) & =-\sum_{t=1}^{T} \frac{\partial}{\partial \eta_{i}} E\left[f\left(\alpha y_{i t-1}+\beta x_{i t-1}+\eta_{i}\right) \mid y_{0}, \eta_{i}, x_{i}\right] \\
& =\frac{\partial}{\partial \eta_{i}} \operatorname{Pr}\left(y_{i t-1}=1 \mid y_{i 0}, \eta_{i}, x_{i}\right)\left(f\left(\alpha+\beta x_{i t-1}+\eta_{i}\right)-f\left(\beta x_{i t-1}+\eta_{i}\right)\right) \\
& +\operatorname{Pr}\left(y_{i t-1}=1 \mid y_{i 0}, \eta_{i}, x_{i}\right)\left(f^{\prime}\left(\alpha+\beta x_{i t-1}+\eta_{i}\right)-f^{\prime}\left(\beta x_{i t-1}+\eta_{i}\right)\right) \\
& +f^{\prime}\left(\beta x_{i t-1}+\eta_{i}\right) .
\end{aligned}
$$

The individual score corresponding to the slope parameters, i.e. $\beta$, can be computed in a similar way. Nevertheless, we must take into account the fact that $\partial F / \partial \beta_{k}=x_{i t, k} f$, where $x_{i t, k}$ is the $k^{t h}$ explanatory variable, which is known, contrary to $y_{t-1}$ from the score corresponding to the lagged binary variable parameter $\alpha$.

As for the variance-covariance matrix, it is the inverse of the the MMLE Hessian matrix, which is calculated accounting for the fixed effects by using the following formula: ${ }^{17}$

$$
\begin{aligned}
& \sum_{i=1}^{N}\left(\frac{\partial^{2} \log \mathrm{L}_{i}\left(\theta, \hat{\eta}_{i}(\theta)\right)}{\partial \theta \partial \theta}+\left.\frac{\partial^{2} \operatorname{LogL}\left(\theta, \eta_{i}\right)}{\partial \theta \partial \eta_{i}}\right|_{\eta_{i}=\hat{\eta}_{i}(\theta)} \frac{\partial \hat{\eta}_{i}(\theta)}{\partial \theta}\right. \\
& \left.+\left[\left.\frac{\partial^{2} \operatorname{LogL}_{i}\left(\theta, \eta_{i}(\theta)\right)}{\partial \eta_{i} \partial \theta}\right|_{\eta_{i}=\hat{\eta}_{i}(\theta)}+\left.\frac{\partial^{2} \log \mathrm{L}_{i}\left(\theta, \eta_{i}(\theta)\right)}{\partial \eta_{i} \partial \eta_{i}}\right|_{\eta_{i}=\hat{\eta}_{i}(\theta)} \frac{\partial \hat{\eta}_{i}(\theta)}{\partial \theta}\right] \frac{\partial \hat{\eta}_{i}(\theta)}{\partial \theta}\right) .
\end{aligned}
$$

17. It is also possible to correct for autocorrelation as in the case of time-series models, by using a "sandwich estimator" for the variance-covariance matrix. 

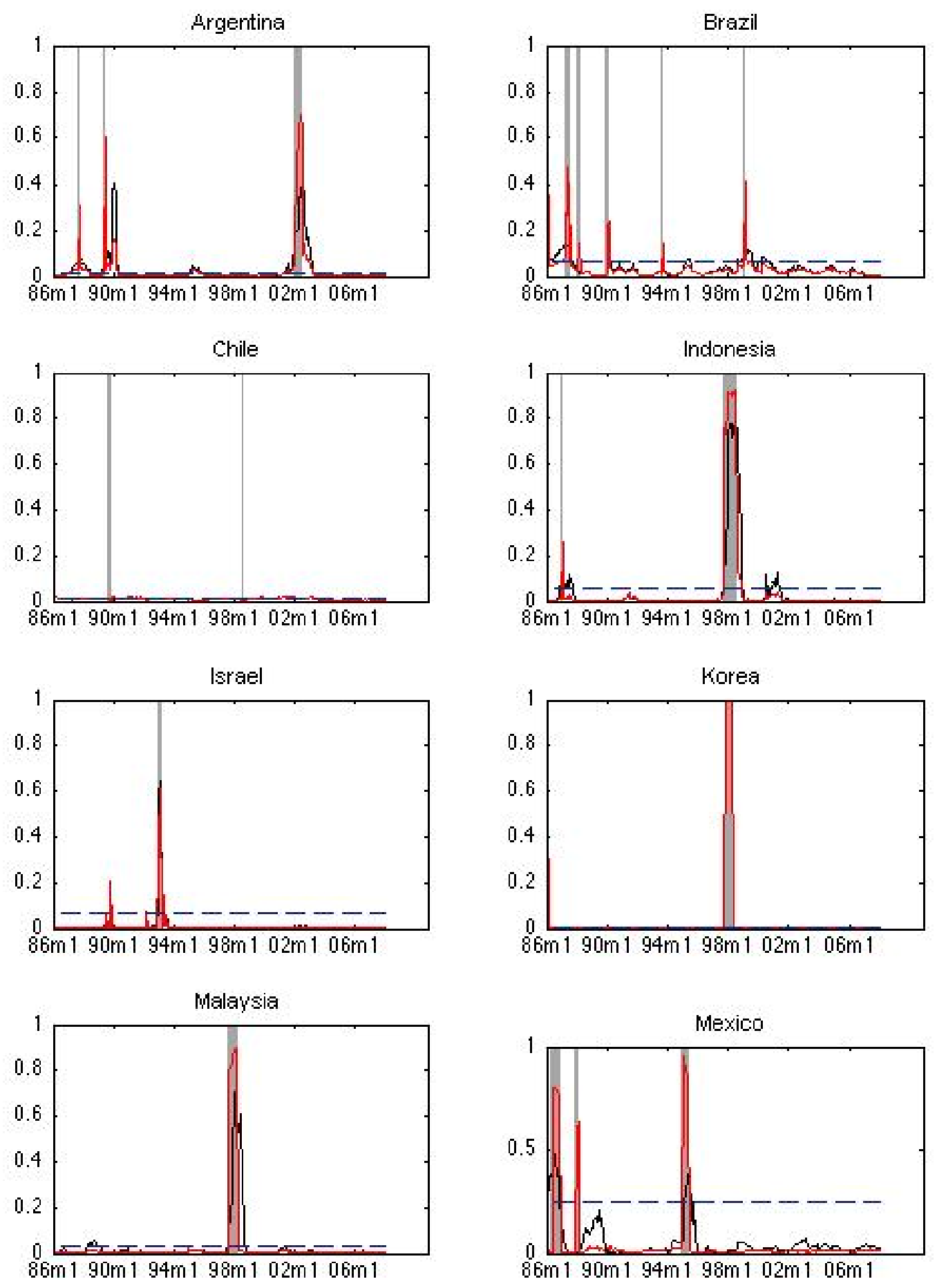

FIgURE 1 - Predicted probability of crisis - in sample 

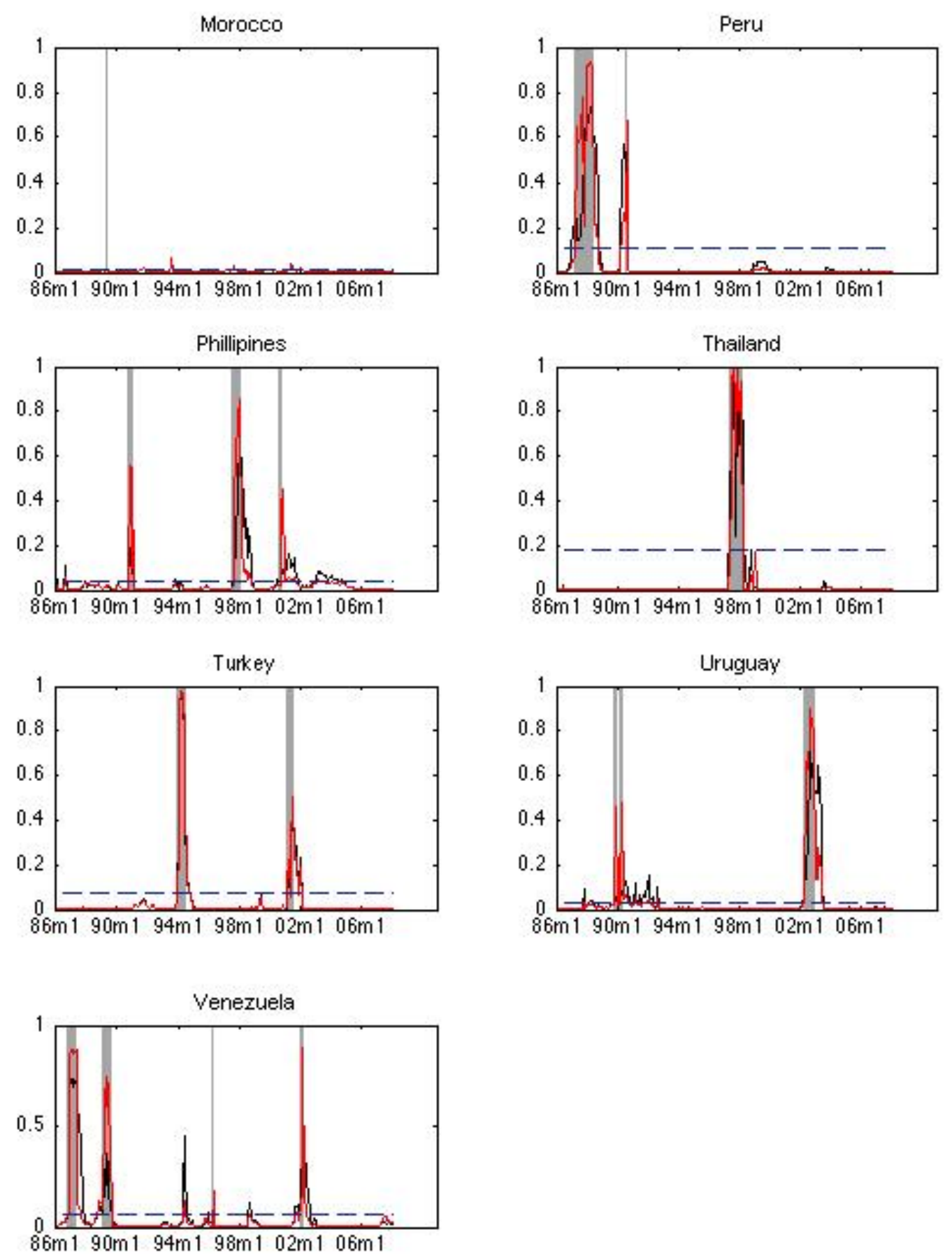

Dbsenved Crises

Static Model

Dynamic Model --- Cut-off

FiguRE 2 - Predicted probability of crisis - in sample (continued) 

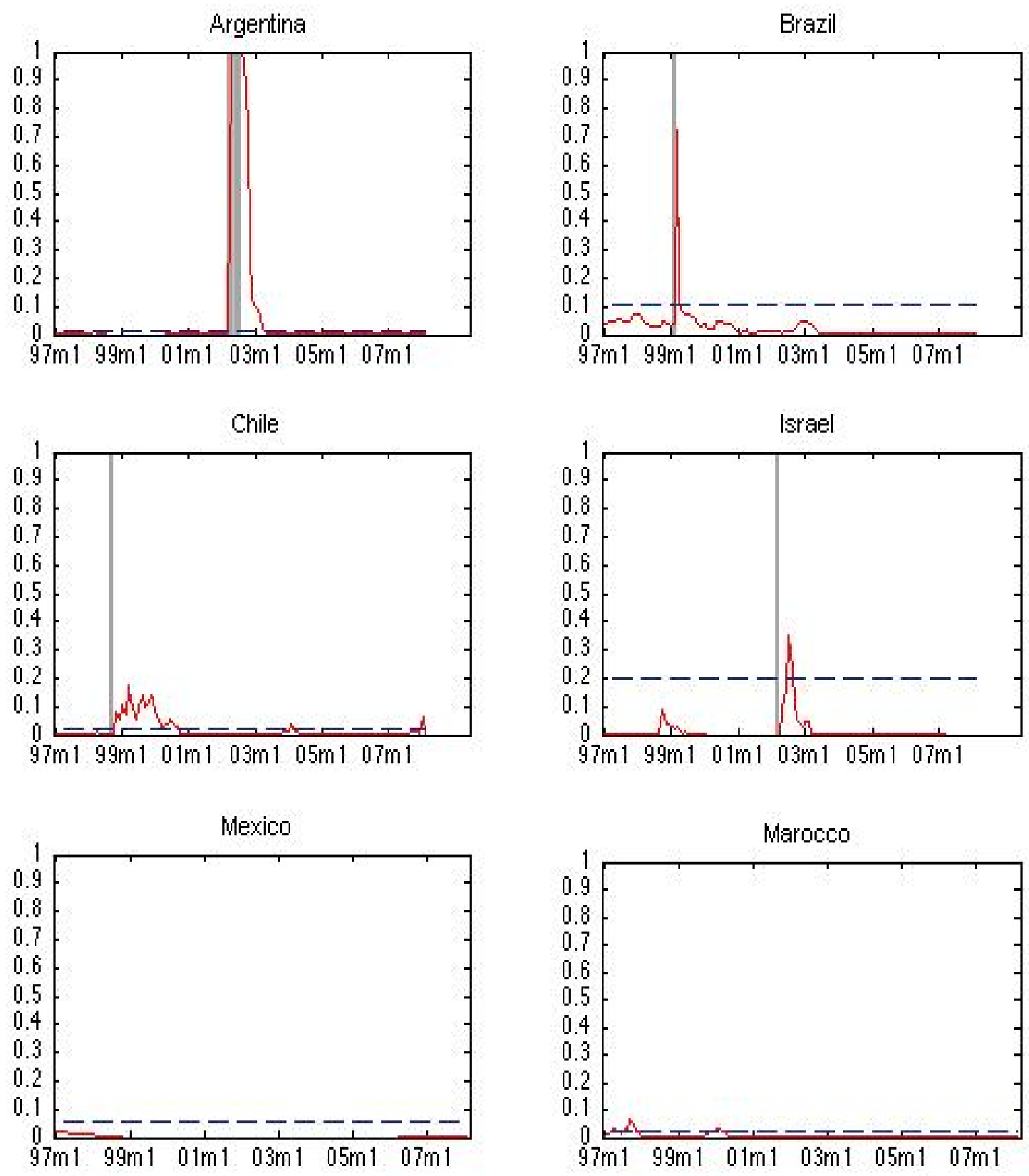

\section{Obsenved Crises - Dut-of-sample Dynamic Model --- Cut-off}

FiguRE 3 - Predicted probability of crisis (one-step-ahead forecasts) - out-of-sample 

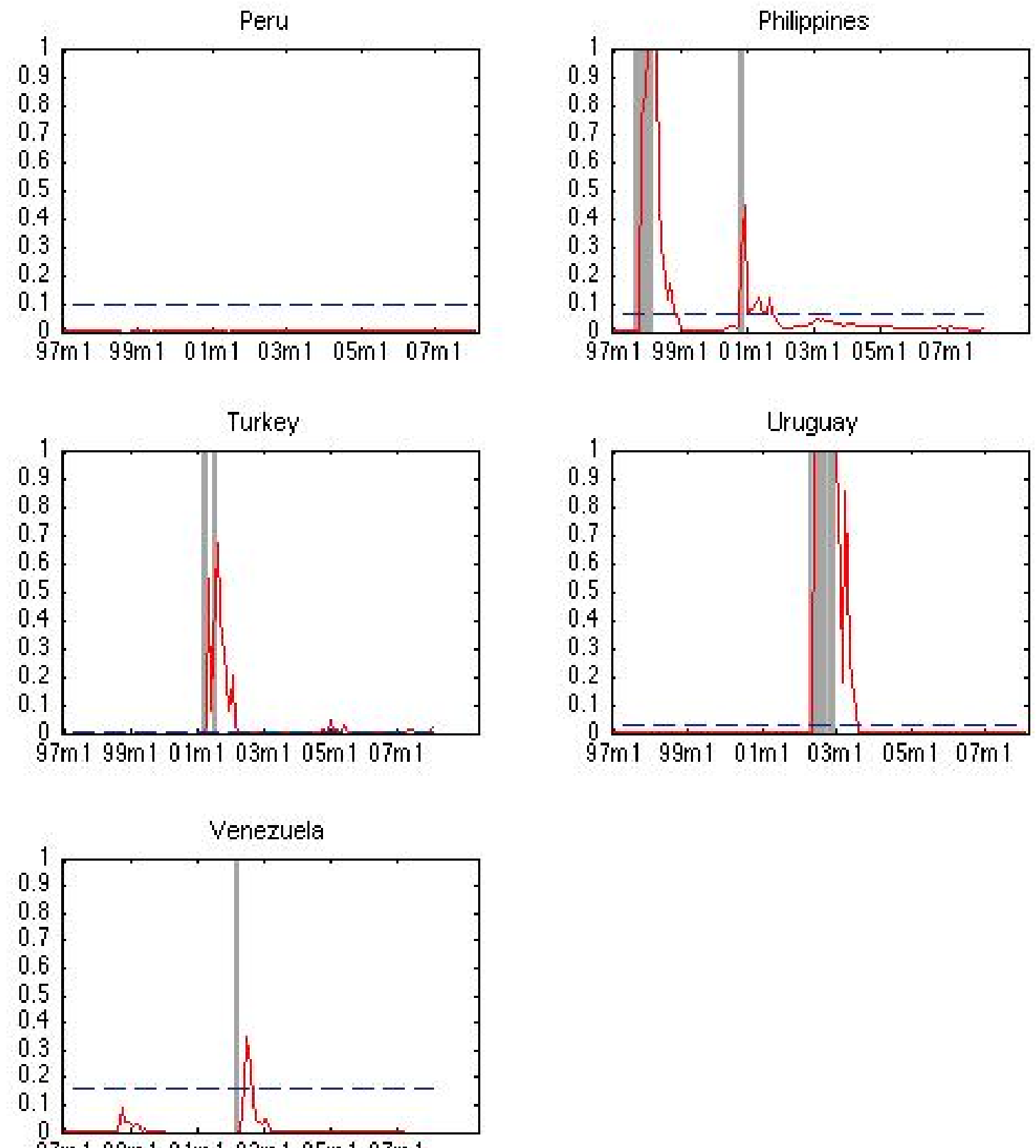

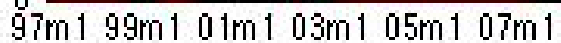

Obsenved Crises

Qut-of-sample Dynamic Model $\quad---$ Cut-off

FiguRE 4 - Predicted probability of crisis (one-step-ahead forecasts) - out-of-sample (continued) 

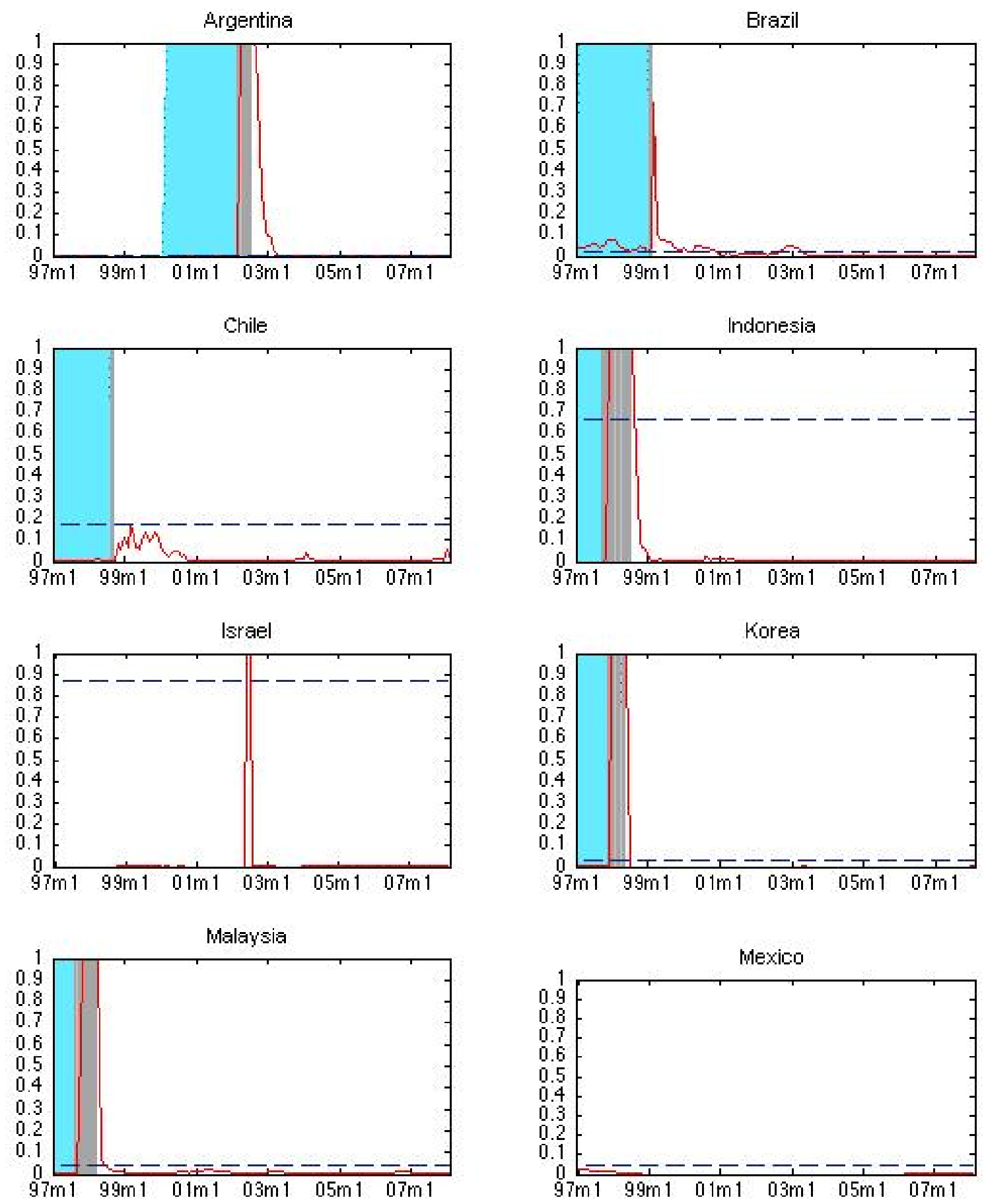

…… 24 months Crisis Dosenued Crises - Out-of-sample Dynamic Model - - Cut-off

FiguRE 5 - Predicted probability of crisis (24-months-ahead forecasts) - out-of-sample 

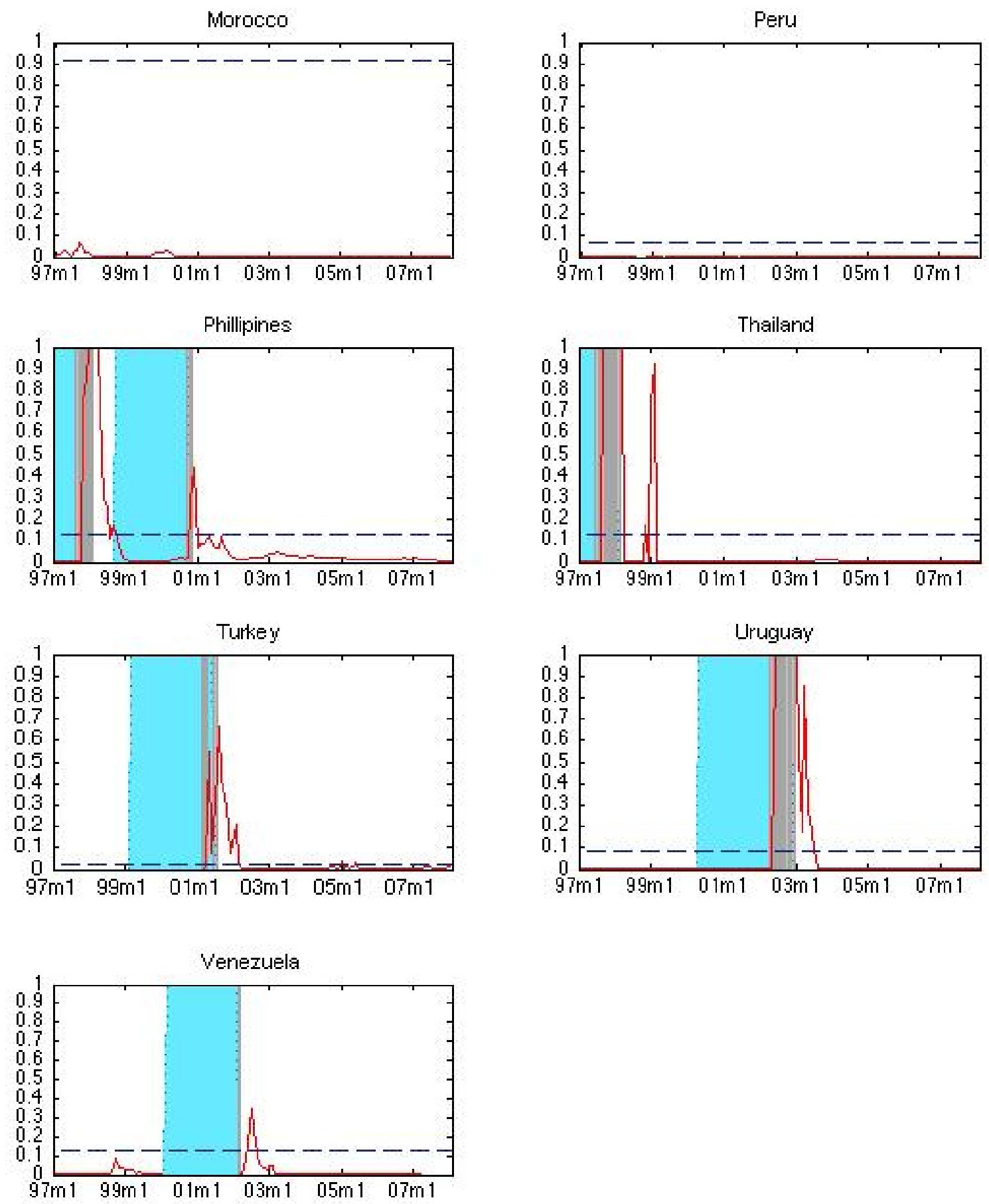

\begin{tabular}{|c|c|c|}
\hline 24 months Crisis & Obsenued Crises & - Qut-of-sample Dynamic Model \\
\hline
\end{tabular}

FiguRE 6 - Predicted probability of crisis (24-months-ahead forecasts) - out-of-sample (continued) 
TABLE 1 - Estimation results of the time-series logit models

\begin{tabular}{|c|c|c|c|c|c|}
\hline \multirow[b]{2}{*}{ Country } & \multirow[b]{2}{*}{ Indicator } & \multicolumn{4}{|c|}{ Coefficient } \\
\hline & & Model 1 & Model 2 & Model 3 & Model 4 \\
\hline \multirow{5}{*}{ Argentina } & Intercept & $\begin{array}{l}-4.905 * * * \\
(1.117)\end{array}$ & $\begin{array}{l}-4.828^{* * *} \\
(0.809)\end{array}$ & $\begin{array}{l}-4.432^{* * *} \\
(1.158)\end{array}$ & $\begin{array}{l}-4.184^{* * *} \\
(1.047)\end{array}$ \\
\hline & Lagged binary variable & & $\begin{array}{l}2.527^{* *} \\
(1.062)\end{array}$ & & $\begin{array}{l}2.384^{* *} \\
(0.915)\end{array}$ \\
\hline & Growth of international reserves & $\begin{array}{l}-7.703^{* *} \\
(3.783)\end{array}$ & $\begin{array}{l}-5.398^{*} \\
(2.676)\end{array}$ & $\begin{array}{l}-7.135^{* * *} \\
(3.266)\end{array}$ & $\begin{array}{l}-4.832^{* *} \\
(2.255)\end{array}$ \\
\hline & Growth of M2 to reserves & $\begin{array}{l}-1.602 \\
(1.051)\end{array}$ & $\begin{array}{l}-1.156 \\
(0.806)\end{array}$ & $\begin{array}{l}-1.394 \\
(0.955)\end{array}$ & $\begin{array}{l}-0.880 \\
(0.693)\end{array}$ \\
\hline & Lagged index & & & $\begin{array}{l}0.106 \\
(0.107)\end{array}$ & $\begin{array}{l}0.143 \\
(0.135)\end{array}$ \\
\hline \multirow{5}{*}{ Brazil } & Intercept & $\begin{array}{l}-3.293^{* * *} \\
(0.481)\end{array}$ & $\begin{array}{l}-3.579^{* * *} \\
(0.423)\end{array}$ & $\begin{array}{l}-0.621^{* * *} \\
(0.167)\end{array}$ & $\begin{array}{l}-0.808^{* * *} \\
(0.246)\end{array}$ \\
\hline & Lagged binary variable & & $\begin{array}{l}2.363^{* * *} \\
(0.874)\end{array}$ & & $\begin{array}{l}0.655 \\
(0.596)\end{array}$ \\
\hline & Growth of international reserves & $\begin{array}{l}-3.289 \\
(1.997)\end{array}$ & $\begin{array}{l}-2.433 \\
(1.753)\end{array}$ & $\begin{array}{l}-1.087^{* * *} \\
(0.285)\end{array}$ & $\begin{array}{l}-1.034^{* * * *} \\
(0.330)\end{array}$ \\
\hline & Growth of M2 to reserves & $\begin{array}{l}-0.047 \\
(0.069)\end{array}$ & $\begin{array}{l}-0.042 \\
(0.057)\end{array}$ & $\begin{array}{l}0.017^{* * *} \\
(0.004)\end{array}$ & $\begin{array}{l}0.018^{* * *} \\
(0.004)\end{array}$ \\
\hline & Lagged index & & & $\begin{array}{l}0.835^{* * *} \\
(0.039)\end{array}$ & $\begin{array}{l}0.794^{* * *} \\
(0.060)\end{array}$ \\
\hline \multirow{5}{*}{ Chile } & Intercept & $\begin{array}{l}-4.413^{* * *} \\
(0.747)\end{array}$ & $\begin{array}{l}-4.405^{* * *} \\
(0.758)\end{array}$ & $\begin{array}{l}-2.104^{* * *} \\
(0.812)\end{array}$ & $\begin{array}{l}-0.984^{* *} \\
(0.478)\end{array}$ \\
\hline & Lagged binary variable & & $\begin{array}{l}-4.140^{* * *} \\
(1.397)\end{array}$ & & $\begin{array}{l}1.613^{*} \\
(0.900)\end{array}$ \\
\hline & Growth of international reserves & $\begin{array}{l}-1.447 \\
(3.754)\end{array}$ & $\begin{array}{l}-1.395 \\
(3.839)\end{array}$ & $\begin{array}{l}-0.086 \\
(0.312)\end{array}$ & $\begin{array}{l}0.788^{* * *} \\
(0.282)\end{array}$ \\
\hline & Growth of M2 to reserves & $\begin{array}{l}-3.029 \\
(2.303)\end{array}$ & $\begin{array}{l}-3.051 \\
(2.359)\end{array}$ & $\begin{array}{l}-0.993 \\
(0.968)\end{array}$ & $\begin{array}{l}0.090 \\
(0.091)\end{array}$ \\
\hline & Lagged index & & & $\begin{array}{l}0.531^{* * *} \\
(0.158)\end{array}$ & $\begin{array}{l}0.809^{* * *} \\
(0.098)\end{array}$ \\
\hline \multirow{5}{*}{ Indonesia } & Intercept & $\begin{array}{l}-5.583^{* * *} \\
(0.927)\end{array}$ & $\begin{array}{l}-5.640^{* * *} \\
(0.913)\end{array}$ & $\begin{array}{l}-8.501^{* * *} \\
(2.009)\end{array}$ & $\begin{array}{l}-6.971^{* * *} \\
(1.334)\end{array}$ \\
\hline & Lagged binary variable & & $\begin{array}{l}3.961^{* * *} \\
(1.454)\end{array}$ & & $\begin{array}{l}4.246^{* *} \\
(1.886)\end{array}$ \\
\hline & Growth of international reserves & $\begin{array}{l}-2.738 \\
(3.912)\end{array}$ & $\begin{array}{l}-0.086 \\
(3.967)\end{array}$ & $\begin{array}{l}-5.183 \\
(8.408)\end{array}$ & $\begin{array}{l}-0.537 \\
(5.706)\end{array}$ \\
\hline & Growth of M2 to reserves & $\begin{array}{l}-10.12^{* * *} \\
(2.608)\end{array}$ & $\begin{array}{l}-6.355^{* * * *} \\
(1.938)\end{array}$ & $\begin{array}{l}-15.45^{* * *} \\
(5.029)\end{array}$ & $\begin{array}{l}-8.574^{* * *} \\
(3.224)\end{array}$ \\
\hline & Lagged index & & & $\begin{array}{l}-0.481^{* * *} \\
(0.083)\end{array}$ & $\begin{array}{r}7-0.207 \\
(0.169) \\
\end{array}$ \\
\hline \multirow{5}{*}{ Israel } & Intercept & $\begin{array}{l}-8.228^{* * *} \\
(1.418)\end{array}$ & $\begin{array}{c}-23.07^{* *} \\
(11.063)\end{array}$ & $\begin{array}{l}-9.323^{* * *} \\
(2.382)\end{array}$ & $\begin{array}{l}-37.22 \\
(65.094)\end{array}$ \\
\hline & Lagged binary variable & & $\begin{array}{l}-10.10 \\
(6.360)\end{array}$ & & $\begin{array}{l}-20.65 \\
(37.37)\end{array}$ \\
\hline & Growth of international reserves & $\begin{array}{l}-54.41^{* * *} \\
(10.26)\end{array}$ & $\begin{array}{l}-209.8^{*} \\
(112.3)\end{array}$ & $\begin{array}{l}-59.41^{* * *} \\
(10.89)\end{array}$ & $\begin{array}{l}-374.2 \\
(669.5)\end{array}$ \\
\hline & Growth of M2 to reserves & $\begin{array}{l}-22.64^{* * *} \\
(4.615)\end{array}$ & $\begin{array}{l}-89.33^{*} \\
(47.22)\end{array}$ & $\begin{array}{l}-23.81^{* * *} \\
(5.249)\end{array}$ & $\begin{array}{l}-168.5 \\
(304.3)\end{array}$ \\
\hline & Lagged index & & & $\begin{array}{l}-0.124 \\
(0.155)\end{array}$ & $\begin{array}{l}0.157^{* *} \\
(0.079)\end{array}$ \\
\hline
\end{tabular}

Note: The standard errors are reported in the parentheses. Significance at one percent level is denoted by ***, at five percent level by $* *$ and at ten percent level by *. 
TABLE 2 - Estimation results of the time-series logit models (continued)

\begin{tabular}{|c|c|c|c|c|c|}
\hline \multirow[b]{2}{*}{ Country } & \multirow[b]{2}{*}{ Indicator } & \multicolumn{4}{|c|}{ "Coefficient } \\
\hline & & Model 1 & Model 2 & Model 3 & Model 4 \\
\hline \multirow{5}{*}{ South Korea } & Intercept & $\begin{array}{l}-33.65 * * * \\
(5.959)\end{array}$ & $\begin{array}{l}-41.55^{* * *} \\
(7.351)\end{array}$ & $\begin{array}{l}-24.83 \\
(68.57)\end{array}$ & $\begin{array}{l}-303.6 \\
(25930)\end{array}$ \\
\hline & Lagged binary variable & & $\begin{array}{l}76.76^{* * *} \\
(17.19)\end{array}$ & & $\begin{array}{l}466.7 \\
(39249)\end{array}$ \\
\hline & Growth of international reserves & $\begin{array}{l}-265.9^{* * *} \\
(48.85)\end{array}$ & $\begin{array}{l}-266.6^{* * *} \\
(40.94)\end{array}$ & $\begin{array}{l}-314.2 \\
(1158)\end{array}$ & $\begin{array}{l}-1033 \\
(82816)\end{array}$ \\
\hline & Growth of M2 to reserves & $\begin{array}{l}-176.9^{* * *} \\
(31.83)\end{array}$ & $\begin{array}{l}-31.05^{* * *} \\
(9.330)\end{array}$ & $\begin{array}{l}-131.0 \\
(385.3)\end{array}$ & $\begin{array}{l}-178.4 \\
(20333)\end{array}$ \\
\hline & Lagged index & & & $\begin{array}{l}(0.511) \\
(0.397) \\
\end{array}$ & $\begin{array}{l}(-0.623) \\
(11.96) \\
\end{array}$ \\
\hline \multirow{5}{*}{ Malaysia } & Intercept & $\begin{array}{l}-4.253^{* * *} \\
(0.760)\end{array}$ & $\begin{array}{l}-5.246 * * * \\
(1.039)\end{array}$ & $\begin{array}{l}-5.952^{* * *} \\
(1.144)\end{array}$ & $\begin{array}{l}-6.177^{* * *} \\
(1.197)\end{array}$ \\
\hline & Lagged binary variable & & $\begin{array}{l}6.092^{* * *} \\
(1.752)\end{array}$ & & $\begin{array}{l}6.596^{* * *} \\
(2.035)\end{array}$ \\
\hline & Growth of international reserves & $\begin{array}{l}-12.78^{* * *} \\
(2.759)\end{array}$ & $\begin{array}{l}-5.090 \\
(4.138)\end{array}$ & $\begin{array}{l}-17.21^{* * *} \\
(4.967)\end{array}$ & $\begin{array}{l}-6.822 \\
(5.363)\end{array}$ \\
\hline & Growth of M2 to reserves & $\begin{array}{l}-5.640^{* * *} \\
(1.723)\end{array}$ & $\begin{array}{c}-0.448 \\
(1.895)\end{array}$ & $\begin{array}{l}-8.381^{* *} \\
(3.447)\end{array}$ & $\begin{array}{l}-1.656 \\
(1.985)\end{array}$ \\
\hline & Lagged index & & & $\begin{array}{l}-0.374^{* *} \\
(0.150)\end{array}$ & $\begin{array}{l}-0.188^{* * *} \\
(0.071)\end{array}$ \\
\hline \multirow{5}{*}{ Mexico } & Intercept & $\begin{array}{l}-3.188^{* * *} \\
(0.681)\end{array}$ & $\begin{array}{l}-4.343^{* * *} \\
(0.684)\end{array}$ & $\begin{array}{l}-4.290^{* * *} \\
(0.801)\end{array}$ & $\begin{array}{l}-5.200^{* * *} \\
(0.883)\end{array}$ \\
\hline & Lagged binary variable & & $\begin{array}{l}5.927^{* * *} \\
(1.893)\end{array}$ & & $\begin{array}{l}6.932^{* * * *} \\
(2.639)\end{array}$ \\
\hline & Growth of international reserves & $\begin{array}{l}-5.135 \\
(3.298)\end{array}$ & $\begin{array}{l}-0.746 \\
(2.459)\end{array}$ & $\begin{array}{l}-6.857 \\
(5.033)\end{array}$ & $\begin{array}{l}-1.221 \\
(3.665)\end{array}$ \\
\hline & Growth of M2 to reserves & $\begin{array}{l}-2.543 \\
(1.983)\end{array}$ & $\begin{array}{l}1.173 \\
(3.662)\end{array}$ & $\begin{array}{l}-3.452 \\
(3.510)\end{array}$ & $\begin{array}{l}1.383 \\
(4.995)\end{array}$ \\
\hline & Lagged index & & & $\begin{array}{l}-0.329 \\
(0.242)\end{array}$ & $\begin{array}{l}-0.196^{* * *} \\
(0.066)\end{array}$ \\
\hline \multirow{5}{*}{ Morocco } & Intercept & $\begin{array}{l}-6.812^{* * *} \\
(1.020)\end{array}$ & $\begin{array}{l}-6.809 * * * \\
(1.033)\end{array}$ & $\begin{array}{l}-1.899 * * * \\
(0.298)\end{array}$ & $\begin{array}{l}-1.530^{* * *} \\
(0.189)\end{array}$ \\
\hline & Lagged binary variable & & $\begin{array}{l}-0.514 \\
(1.866)\end{array}$ & & $\begin{array}{l}-2.588^{* * *} \\
(0.769)\end{array}$ \\
\hline & Growth of international reserves & $\begin{array}{l}-6.700^{* * *} \\
(1.422)\end{array}$ & $\begin{array}{l}-6.699^{* * *} \\
(1.421)\end{array}$ & $\begin{array}{l}-1.473^{* *} \\
(0.687)\end{array}$ & $\begin{array}{l}-1.116^{* *} \\
(0.506)\end{array}$ \\
\hline & Growth of M2 to reserves & $\begin{array}{l}-17.80^{* * *} \\
(2.960)\end{array}$ & $\begin{array}{l}-17.79^{* * *} \\
(2.960)\end{array}$ & $\begin{array}{l}-4.971^{* * *} \\
(1.687\end{array}$ & $\begin{array}{l}-3.897^{* * *} \\
(1.240)\end{array}$ \\
\hline & Lagged index & & & $\begin{array}{l}0.729^{* * *} \\
(0.042)\end{array}$ & $\begin{array}{l}0.777^{* * *} \\
(0.025)\end{array}$ \\
\hline \multirow{5}{*}{ Peru } & Intercept & $\begin{array}{l}-5.151^{* * *} \\
(0.961)\end{array}$ & $\begin{array}{l}-5.939 * * * \\
(0.840)\end{array}$ & $\begin{array}{l}-2.787^{* * *} \\
(0.709)\end{array}$ & $\begin{array}{l}-6.793^{* * *} \\
(2.993)\end{array}$ \\
\hline & Lagged binary variable & & $\begin{array}{l}3.264^{* * *} \\
(0.999)\end{array}$ & & $\begin{array}{l}3.600^{* * *} \\
(1.341)\end{array}$ \\
\hline & Growth of international reserves & $\begin{array}{l}-13.23^{* * *} \\
(2.519)\end{array}$ & $\begin{array}{l}-11.77^{* * *} \\
(2.808)\end{array}$ & $\begin{array}{l}-7.706^{* * *} \\
(1.626)\end{array}$ & $\begin{array}{l}-13.44^{*} \\
(7.037)\end{array}$ \\
\hline & Growth of M2 to reserves & $\begin{array}{l}-0.476 \\
(0.696)\end{array}$ & $\begin{array}{l}-0.574 \\
(0.712)\end{array}$ & $\begin{array}{l}-0.439 \\
(0.253)\end{array}$ & $\begin{array}{l}-0.525 \\
(0.941)\end{array}$ \\
\hline & Lagged index & & & $\begin{array}{l}0.477^{* * *} \\
(0.094)\end{array}$ & $\begin{array}{l}-0.144 \\
(0.493)\end{array}$ \\
\hline
\end{tabular}

Note: The standard errors are reported in the parentheses. Significance at one percent level is denoted by ***, at five percent level by $* *$ and at ten percent level by *. 
TABLE 3 - Estimation results of the time-series logit models (continued)

\begin{tabular}{|c|c|c|c|c|c|}
\hline & & & Coef & icient & \\
\hline Country & Indicator & Model 1 & Model 2 & Model 3 & Model 4 \\
\hline & Intercept & $\begin{array}{l}-3.300^{* * *} \\
(0.532)\end{array}$ & $\begin{array}{l}-3.754^{* * *} \\
(0.534)\end{array}$ & $\begin{array}{l}-5.178^{* * *} \\
(1.319)\end{array}$ & $\begin{array}{l}-5.647^{* * *} \\
1.590)\end{array}$ \\
\hline & Lagged binary variable & & $\begin{array}{l}2.967^{* * *} \\
(1.131)\end{array}$ & & $\begin{array}{l}2.832^{* *} \\
(1.299)\end{array}$ \\
\hline Philippines & Growth of international reserves & $\begin{array}{l}-10.595^{* * *} \\
(3.192)\end{array}$ & $\begin{array}{l}-7.135^{* *} \\
(3.261)\end{array}$ & $\begin{array}{l}-16.586^{* * *} \\
(5.407)\end{array}$ & $\begin{array}{l}-15.833^{* *} \\
(6.510)\end{array}$ \\
\hline & Growth of M2 to reserves & $\begin{array}{l}-5.645^{* * *} \\
(1.427)\end{array}$ & $\begin{array}{l}-3.280^{* *} \\
(1.296)\end{array}$ & $\begin{array}{l}-8.879^{* * *} \\
(2.702)\end{array}$ & $\begin{array}{l}-6.493^{* * *} \\
(2.470)\end{array}$ \\
\hline & Lagged index & & & $\begin{array}{l}-0.473^{* * *} \\
(0.121)\end{array}$ & $\begin{array}{l}-0.436 \\
(0.233)\end{array}$ \\
\hline & Intercept & $\begin{array}{l}-6.387^{* * *} \\
(1.545)\end{array}$ & $\begin{array}{l}-8.068^{* * *} \\
(2.776)\end{array}$ & $\begin{array}{l}-13.81 \\
(32.12)\end{array}$ & $\begin{array}{l}-12.30 \\
24.86)\end{array}$ \\
\hline & Lagged binary variable & & $\begin{array}{l}5.497^{* * *} \\
(1.496)\end{array}$ & & $\begin{array}{l}2.514^{* * *} \\
(1.205)\end{array}$ \\
\hline Thailand & Growth of international reserves & $\begin{array}{l}-40.56^{* * *} \\
(11.65)\end{array}$ & $\begin{array}{l}-35.99 \\
(20.73)\end{array}$ & $\begin{array}{l}-113.1 \\
(266.6)\end{array}$ & $\begin{array}{l}-87.37 \\
(208.7)\end{array}$ \\
\hline & Growth of M2 to reserves & $\begin{array}{l}5.873^{* *} \\
(2.790)\end{array}$ & $\begin{array}{l}10.84^{* *} \\
(4.866)\end{array}$ & $\begin{array}{l}37.13 \\
(90.47)\end{array}$ & $\begin{array}{l}29.79 \\
(70.38)\end{array}$ \\
\hline & Lagged index & & & $\begin{array}{l}0.579^{* * *} \\
(0.043)\end{array}$ & $\begin{array}{l}0.525^{* * *} \\
(0.180)\end{array}$ \\
\hline & Intercept & $\begin{array}{l}-5.721^{* * *} \\
(1.627)\end{array}$ & $\begin{array}{l}-5.556^{* * *} \\
(1.651)\end{array}$ & $\begin{array}{l}-10.21 \\
(6.460)\end{array}$ & $\begin{array}{l}-10.90 \\
(6.817)\end{array}$ \\
\hline & Lagged binary variable & & $\begin{array}{l}0.767 \\
(1.609)\end{array}$ & & $\begin{array}{l}2.253 \\
(1.507)\end{array}$ \\
\hline Turkey & Growth of international reserves & $-15.11^{* * *}$ & $-13.43^{* *}$ & -29.89 & -27.99 \\
\hline & & $\begin{array}{l}(3.997) \\
-4.562 * *\end{array}$ & $(5.899)$ & $\begin{array}{c}(22.26) \\
7.202\end{array}$ & $\begin{array}{l}(24.67) \\
-7.443\end{array}$ \\
\hline & Growth of M2 to reserves & $(2.045)$ & $\begin{array}{l}-4.241 \\
(2.545)\end{array}$ & $(4.589)$ & $\begin{array}{l}-1.445 \\
(6.055)\end{array}$ \\
\hline & Lagged index & & & $\begin{array}{l}-0.502^{* * *} \\
(0.095)\end{array}$ & $\begin{array}{l}-0.617^{* * *} \\
(0.166)\end{array}$ \\
\hline & Intercept & $\begin{array}{l}-4.717^{* * *} \\
(0.693)\end{array}$ & $\begin{array}{l}-5.053^{* * *} \\
(0.634)\end{array}$ & $\begin{array}{l}-7.485^{* * *} \\
(2.309)\end{array}$ & $\begin{array}{l}-4.464^{* * *} \\
(0.931)\end{array}$ \\
\hline & Lagged binary variable & & $\begin{array}{l}2.971^{* * *} \\
(1.046)\end{array}$ & & $\begin{array}{l}2.923^{* * *} \\
(0.926)\end{array}$ \\
\hline Uruguay & Growth of international reserves & $\begin{array}{l}-10.17^{* * *} \\
(2.638)\end{array}$ & $\begin{array}{l}-7.704^{* * *} \\
(1.776)\end{array}$ & $\begin{array}{l}-15.731^{* * *} \\
(4.845)\end{array}$ & $\begin{array}{l}-6.640^{* * *} \\
(2.196)\end{array}$ \\
\hline & Growth of M2 to reserves & $\begin{array}{l}-2.336 \\
(2.404)\end{array}$ & $\begin{array}{l}-2.803 \\
(1.735)\end{array}$ & $\begin{array}{l}7-3.053 \\
(2.947)\end{array}$ & $\begin{array}{l}-3.017^{* *} \\
(1.521)\end{array}$ \\
\hline & Lagged index & & & $\begin{array}{l}-0.537^{* *} \\
(0.246)\end{array}$ & $\begin{array}{l}0.136 \\
(0.159)\end{array}$ \\
\hline & Intercept & $\begin{array}{l}-6.088^{* * *} \\
(1.111)\end{array}$ & $\begin{array}{l}-5.914^{* * *} \\
(1.196)\end{array}$ & $\begin{array}{l}-1.427^{* * *} \\
(0.389)\end{array}$ & $\begin{array}{l}-5.304^{* * *} \\
(1.309)\end{array}$ \\
\hline & Lagged binary variable & & $\begin{array}{l}3.470^{* *} \\
(1.432)\end{array}$ & & $\begin{array}{l}3.370^{* * *} \\
(1.210)\end{array}$ \\
\hline Venezuela & Growth of international reserves & $\begin{array}{l}-15.48^{* * *} \\
(4.092)\end{array}$ & $\begin{array}{l}-11.72^{* * *} \\
(4.059)\end{array}$ & $\begin{array}{l}-4.779 * * * \\
(1.233)\end{array}$ & $\begin{array}{l}-10.33^{* * *} \\
(3.884)\end{array}$ \\
\hline & Growth of M2 to reserves & $\begin{array}{l}-2.164^{* *} \\
(0.940)\end{array}$ & $\begin{array}{l}-0.235 \\
(1.314)\end{array}$ & $\begin{array}{l}0.359^{* * *} \\
(0.115)\end{array}$ & $\begin{array}{l}0.017 \\
(1.338)\end{array}$ \\
\hline & Lagged index & & & $\begin{array}{l}0.804^{* * *} \\
(0.037)\end{array}$ & $\begin{array}{l}0.103 \\
(0.207)\end{array}$ \\
\hline
\end{tabular}

Note:The standard errors are reported in the parentheses. Significance at one percent level is denoted by ***, at five percent level by ** and at ten percent level by *. 
TABLE 4 - SBC information criterion for the time-series logit models

\begin{tabular}{lllll}
\hline \hline Country & Model 1 & Model 2 & Model 3 & Model 4 \\
\hline & SBC & SBC & SBC & SBC \\
\hline Argentina & 57.62 & $\mathbf{5 7 . 4 7}$ & 63.07 & 62.72 \\
Brazil & 88.39 & 87.72 & $\mathbf{8 7 . 2 0}$ & 91.94 \\
Chile & $\mathbf{4 9 . 0 3}$ & 54.53 & 54.81 & 58.68 \\
Indonesia & 54.90 & $\mathbf{4 9 . 8 0}$ & 58.70 & 55.05 \\
Israel & $\mathbf{2 6 . 4 2}$ & 30.49 & 31.88 & 35.14 \\
South Korea & $\mathbf{1 6 . 7 5}$ & 22.33 & 22.33 & 31.44 \\
Malaysia & 50.16 & $\mathbf{4 0 . 3 5}$ & 54.51 & 45.66 \\
Mexico & 101.1 & $\mathbf{6 7 . 7 0}$ & 105.4 & 72.29 \\
Marocco & $\mathbf{2 7 . 8 6}$ & 33.43 & 33.60 & 39.15 \\
Peru & 62.50 & $\mathbf{5 3 . 7 3}$ & 66.37 & 59.22 \\
Philippines & 75.14 & $\mathbf{7 0 . 7 5}$ & 76.82 & 75.00 \\
Thailand & 33.21 & 32.47 & $\mathbf{3 0 . 4 3}$ & 35.30 \\
Turkey & $\mathbf{4 4 . 7 8}$ & 50.04 & 45.13 & 48.86 \\
Uruguay & 62.06 & $\mathbf{5 8 . 8 9}$ & 66.65 & 64.35 \\
Venezuela & 74.60 & $\mathbf{6 8 . 0 1}$ & 82.78 & 73.48 \\
\hline \hline
\end{tabular}

Note: Bold values correspond to the best model according to SBC. 
TABLE 5 - Estimation results of the panel logit models

\begin{tabular}{|c|c|c|c|}
\hline \multirow[t]{2}{*}{ Indicator } & \multicolumn{2}{|c|}{ Coefficients } & \multirow[b]{2}{*}{$\begin{array}{c}\text { Poolable countries } \\
\text { (cluster2) }\end{array}$} \\
\hline & All countries & $\begin{array}{c}\text { Poolable countries } \\
\text { (cluster } 1)\end{array}$ & \\
\hline Lagged binary variable & $\begin{array}{c}4.383^{* * *} \\
(0.304)\end{array}$ & $\begin{array}{c}4.294^{* * *} \\
(0.332)\end{array}$ & $\begin{array}{c}3.608^{* * *} \\
(0.955)\end{array}$ \\
\hline Growth of international reserves & $\begin{array}{c}-4.092^{* * *} \\
(0.665)\end{array}$ & $\begin{array}{c}-3.614^{* * *} \\
(0.681)\end{array}$ & $\begin{array}{c}-7.496^{* * *} \\
(2.695)\end{array}$ \\
\hline Growth of M2 to reserves & $\begin{array}{c}-0.542^{*} \\
0.298\end{array}$ & $\begin{array}{l}-0.550^{*} \\
(0.325)\end{array}$ & $\begin{array}{l}-0.459 \\
(0.776)\end{array}$ \\
\hline \multicolumn{4}{|l|}{ Fixed effects } \\
\hline Argentina & -5.083 & -4.919 & -- \\
\hline Brazil & -4.076 & -4.004 & -- \\
\hline Chile & -4.660 & -4.657 & -- \\
\hline Indonesia & -4.066 & -4.030 & -- \\
\hline Israel & -5.308 & -- & -- \\
\hline South Korea & -4.218 & -- & -- \\
\hline Malaysia & -4.436 & -4.375 & -- \\
\hline Mexico & -4.102 & -4.021 & -- \\
\hline Marocco & -5.347 & -- & -5.170 \\
\hline Peru & -4.339 & -- & -4.825 \\
\hline Philippines & -4.096 & -4.033 & -- \\
\hline Thailand & -4.334 & -4.279 & -- \\
\hline Turkey & -4.523 & -4.441 & -- \\
\hline Uruguay & -4.682 & -4.552 & -- \\
\hline Venezuela & -4.577 & -4.450 & -- \\
\hline
\end{tabular}

Note: The standard errors are reported in the parentheses. Significance at one percent level is denoted by ***, at five percent level by ** and at ten percent level by *. 
TABLE 6 - Optimal cut-off identification for time-series models

\begin{tabular}{|c|c|c|c|c|c|c|c|c|c|}
\hline & \multicolumn{3}{|c|}{ Static logit } & \multicolumn{3}{|c|}{ Dynamic logit } & \multicolumn{3}{|c|}{ Dynamic Markov switching } \\
\hline & Cut-off & Sensitivity & Specificity & Cut-off & Sensitivity & Specificity & Cut-off & Sensitivity & Specificity \\
\hline Argentina & 0.011 & 1.000 & 0.767 & 0.010 & 1.000 & 0.767 & 0.672 & 0.857 & 0.857 \\
\hline Brazil & 0.064 & 0.500 & 0.859 & 0.042 & 0.700 & 0.847 & 0.026 & 0.900 & 0.694 \\
\hline Chile & 0.014 & 0.667 & 0.714 & 0.014 & 0.667 & 0.721 & $<0.001$ & 1.000 & $<0.001$ \\
\hline Indonesia & 0.061 & 1.000 & 0.917 & 0.036 & 0.909 & 0.969 & 0.908 & 0.818 & 0.992 \\
\hline Israel & 0.066 & 1.000 & 0.992 & 0.203 & 1.000 & 0.992 & 0.998 & 0.500 & 0.973 \\
\hline South Korea & 0.005 & 1.000 & 1.000 & 0.606 & 1.000 & 1.000 & 0.999 & 1.000 & 0.938 \\
\hline Malaysia & 0.033 & 1.000 & 0.938 & 0.008 & 1.000 & 0.860 & 0.823 & 1.000 & 0.895 \\
\hline Mexico & 0.244 & 0.643 & 0.972 & 0.034 & 0.857 & 0.988 & 0.567 & 1.000 & 0.873 \\
\hline Marocco & 0.010 & 1.000 & 0.883 & 0.010 & 1.000 & 0.883 & 0.000 & 1.000 & 0.000 \\
\hline Peru & 0.112 & 1.000 & 0.944 & 0.069 & 1.000 & 0.956 & 0.998 & 0.077 & 0.960 \\
\hline Philippines & 0.038 & 1.000 & 0.784 & 0.022 & 1.000 & 0.733 & 0.987 & 1.000 & 0.882 \\
\hline Thailand & 0.183 & 1.000 & 0.984 & 0.174 & 1.000 & 0.996 & 0.999 & 0.875 & 0.887 \\
\hline Turkey & 0.071 & 0.889 & 0.957 & 0.107 & 0.889 & 0.969 & 0.897 & 1.000 & 0.957 \\
\hline Uruguay & 0.031 & 1.000 & 0.851 & 0.021 & 1.000 & 0.843 & 0.937 & 1.000 & 0.984 \\
\hline Venezuela & 0.065 & 0.929 & 0.892 & 0.092 & 0.929 & 0.948 & 0.999 & 1.000 & 0.725 \\
\hline
\end{tabular}

Note: For each country we identify the optimal cut-off by using the accuracy measures method, so as to give more weight to the correct identification of crisis periods (sensitivity). 
TABLE 7 - Evaluation criteria for the time-series logit models

\begin{tabular}{|c|c|c|c|c|c|c|}
\hline \multicolumn{7}{|c|}{ Static time-series logit model } \\
\hline Country & $\mathrm{AUC}$ & Kuiper score & Pietra index & Bayesian error rate & QPS & LPS \\
\hline Argentina & 0.938 & 0.767 & 0.271 & 0.026 & 0.043 & 10.07 \\
\hline Brazil & 0.710 & 0.359 & 0.127 & 0.030 & 0.069 & 0.145 \\
\hline Chile & 0.606 & 0.380 & 0.134 & 0.011 & 0.022 & 0.061 \\
\hline Indonesia & 0.979 & 0.917 & 0.324 & 0.026 & 0.044 & 0.072 \\
\hline Israel & 0.994 & 0.992 & 0.351 & 0.008 & 0.011 & 0.018 \\
\hline South Korea & 1.000 & 1.000 & 0.354 & 0.000 & 0.000 & 0.000 \\
\hline Malaysia & 0.978 & 0.938 & 0.332 & 0.023 & 0.039 & 0.063 \\
\hline Mexico & 0.784 & 0.615 & 0.217 & 0.030 & 0.073 & 0.161 \\
\hline Marocco & 0.888 & 0.883 & 0.312 & 0.004 & 0.008 & 0.021 \\
\hline Peru & 0.974 & 0.944 & 0.334 & 0.030 & 0.059 & 0.086 \\
\hline Philippines & 0.915 & 0.784 & 0.277 & 0.034 & 0.062 & 0.110 \\
\hline Thailand & 0.995 & 0.984 & 0.348 & 0.011 & 0.021 & 0.031 \\
\hline Turkey & 0.976 & 0.846 & 0.299 & 0.015 & 0.026 & 0.053 \\
\hline Uruguay & 0.959 & 0.851 & 0.301 & 0.026 & 0.051 & 0.086 \\
\hline Venezuela & 0.955 & 0.821 & 0.290 & 0.038 & 0.066 & 0.109 \\
\hline \multicolumn{7}{|c|}{ Dynamic time-series logit model } \\
\hline Country & AUC & Kuiper score & Pietra index & Bayesian error rate & QPS & LPS \\
\hline Argentina & 0.946 & 0.767 & 0.271 & 0.019 & 0.033 & 0.066 \\
\hline Brazil & 0.799 & 0.547 & 0.193 & 0.034 & 0.068 & 0.135 \\
\hline Chile & 0.601 & 0.388 & 0.137 & 0.011 & 0.022 & 0.061 \\
\hline Indonesia & 0.981 & 0.878 & 0.310 & 0.011 & 0.024 & 0.052 \\
\hline Israel & 0.994 & 0.992 & 0.351 & 0.008 & 0.011 & 0.015 \\
\hline South Korea & 1.000 & 1.000 & 0.354 & 0.000 & 0.003 & 0.004 \\
\hline Malaysia & 0.978 & 0.860 & 0.304 & 0.008 & 0.015 & 0.034 \\
\hline Mexico & 0.880 & 0.845 & 0.299 & 0.019 & 0.038 & 0.086 \\
\hline Marocco & 0.888 & 0.883 & 0.312 & 0.004 & 0.008 & 0.021 \\
\hline Peru & 0.989 & 0.956 & 0.338 & 0.023 & 0.038 & 0.059 \\
\hline Philippines & 0.935 & 0.733 & 0.259 & 0.026 & 0.049 & 0.092 \\
\hline Thailand & 0.998 & 0.996 & 0.352 & 0.004 & 0.011 & 0.019 \\
\hline Turkey & 0.978 & 0.858 & 0.303 & 0.015 & 0.027 & 0.052 \\
\hline Uruguay & 0.966 & 0.843 & 0.298 & 0.015 & 0.034 & 0.069 \\
\hline Venezuela & 0.961 & 0.877 & 0.310 & 0.023 & 0.046 & 0.086 \\
\hline
\end{tabular}

Note: The AUC criteria takes values between 0.5 and 1, 1 being the perfect model. Kuiper's score should have positive values if the model identifies well the crisis periods. Pietra index takes values from - 0.354 to 0.354 , the higher its level, the better the model. Bayesian error rate takes values between 0 and 1, 0 corresponding to the perfect model. QPS ranges from 0 to 2,0 being perfect accuracy, while LPS ranges from 0 to $\infty, 0$ being perfect accuracy. 
TABLE 8 - Evaluation criteria for the dynamic Markov-switching model

\begin{tabular}{lcccccc}
\hline \hline Country & AUC & Kuiper score & Pietra index & Bayesian error rate & QPS & LPS \\
\hline Argentina & 0.871 & 0.714 & 0.252 & 0.026 & 0.754 & 1.711 \\
Brazil & 0.783 & 0.594 & 0.210 & 0.038 & 0.502 & 3.807 \\
Chile & 0.010 & 0.000 & 0.000 & 0.011 & 1.198 & 3.661 \\
Indonesia & 0.817 & 0.810 & 0.286 & 0.015 & 1.199 & 1.602 \\
Israel & 0.536 & 0.473 & 0.167 & 0.008 & 0.480 & 1.079 \\
South Korea & 0.969 & 0.938 & 0.332 & 0.023 & 0.171 & 1.081 \\
Malaysia & 0.955 & 0.895 & 0.317 & 0.026 & 0.239 & 1.526 \\
Mexico & 0.971 & 0.873 & 0.308 & 0.023 & 0.598 & 0.903 \\
Marocco & 0.028 & 0.000 & 0.000 & 0.004 & 0.436 & 1.087 \\
Peru & 0.268 & 0.037 & 0.013 & 0.049 & 1.121 & 1.950 \\
Philippines & 0.948 & 0.882 & 0.312 & 0.038 & 0.526 & 1.399 \\
Thailand & 0.828 & 0.762 & 0.269 & 0.030 & 1.203 & 3.108 \\
Turkey & 0.992 & 0.957 & 0.338 & 0.011 & 0.386 & 0.608 \\
Uruguay & 0.995 & 0.984 & 0.348 & 0.011 & 0.546 & 0.814 \\
Venezuela & 0.863 & 0.725 & 0.256 & 0.053 & 0.997 & 5.528 \\
\hline \hline
\end{tabular}

Note: The AUC criteria takes values between 0.5 and 1, 1 being the perfect model. Kuiper's score should have positive values if the model identifies well the crisis periods. Pietra index takes values from - 0.354 to 0.354 , the higher its level, the better the model. Bayesian error rate takes values between 0 and 1, 0 corresponding to the perfect model. QPS ranges from 0 to 2,0 being perfect accuracy, while LPS ranges from 0 to $\infty, 0$ being perfect accuracy. 
TABLE 9 - Comparison tests

\begin{tabular}{|c|c|c|c|c|c|c|}
\hline \multirow[b]{2}{*}{ Country } & \multicolumn{2}{|c|}{$\begin{array}{l}\text { Static vs. dynamic }^{a} \\
\text { (Clark-West test) }\end{array}$} & \multicolumn{2}{|c|}{$\begin{array}{c}\text { Dynamic logit vs. Markov }{ }^{b} \\
\text { (Diebold Mariano test) }\end{array}$} & \multicolumn{2}{|c|}{$\begin{array}{c}\text { Dynamic panel logit vs. Markov } \\
\text { (Diebold Mariano test) }\end{array}$} \\
\hline & test statistic & p-value & test statistic & p-value & test statistic & p-value \\
\hline Argentina & 2.144 & 0.016 & 25.54 & $<0.001$ & 25.61 & $<0.001$ \\
\hline Brazil & 1.136 & 0.128 & 8.004 & $<0.001$ & 7.830 & $<0.001$ \\
\hline Chile & 1.036 & 0.150 & 21.89 & $<0.001$ & 21.71 & $<0.001$ \\
\hline Indonesia & 2.526 & 0.006 & 21.89 & $<0.001$ & 48.04 & $<0.001$ \\
\hline Israel & 0.434 & 0.332 & 10.04 & $<0.001$ & -- & $<0.001$ \\
\hline South Korea & 1.037 & 0.150 & 5.157 & $<0.001$ & -- & $<0.001$ \\
\hline Malaysia & 2.656 & 0.004 & 5.985 & $<0.001$ & 5.885 & $<0.001$ \\
\hline Mexico & 3.291 & $<0.001$ & 29.02 & $<0.001$ & 25.81 & $<0.001$ \\
\hline Marocco & 0.668 & 0.252 & 9.726 & $<0.001$ & 8.701 & $<0.001$ \\
\hline Peru & 2.776 & 0.003 & 40.70 & $<0.001$ & 22.39 & $<0.001$ \\
\hline Philippines & 2.358 & 0.009 & 9.094 & $<0.001$ & 6.976 & $<0.001$ \\
\hline Thailand & 2.067 & 0.019 & 21.77 & $<0.001$ & 18.12 & $<0.001$ \\
\hline Turkey & 2.067 & 0.019 & 11.10 & $<0.001$ & 6.048 & $<0.001$ \\
\hline Uruguay & 2.827 & 0.002 & 14.33 & $<0.001$ & 10.89 & $<0.001$ \\
\hline Venezuela & 2.977 & $<0.001$ & 16.40 & $<0.001$ & 11.98 & $<0.001$ \\
\hline
\end{tabular}

a - Static vs. dynamic time series logit model.

b - Dynamic time-series logit model vs. Markov switching.

c - Dynamic panel logit model (poolable countries) vs. Markov switching.

Note: The null hypothesis of both tests is the equality of predictive performance of the two models. The alternative of the Clark-West test indicates that the non-constraint model (the bigger one) is better than the other one. Under the null hypothesis, the MSPE-adj statistic follows a normal distribution with a critical unilateral value of 1.645(5\%). The alternative of the Diebold Mariano test indicates that the first model is better than the other one. Under the null hypothesis, the test statistic follows a normal distribution. Bold entries indicate significance at the $5 \%$ level. 
TABLE 10 - Optimal cut-off identification for dynamic panel logit models

\begin{tabular}{lccccccc}
\hline \hline & \multicolumn{3}{c}{ All countries } & & \multicolumn{3}{c}{ Poolable countries } \\
\cline { 2 - 3 } \cline { 7 - 8 } & Cut-off & Sensitivity & Specificity & & Cut-off & Sensitivity & Specificity \\
\hline Argentina & 0.025 & 0.857 & 0.942 & & 0.023 & 0.857 & 0.930 \\
Brazil & 0.043 & 0.700 & 0.894 & & 0.043 & 0.700 & 0.898 \\
Chile & 0.015 & 0.333 & 0.973 & & 0.014 & 0.333 & 0.966 \\
Indonesia & 0.046 & 0.909 & 0.984 & & 0.043 & 0.909 & 0.984 \\
Israel & 0.008 & 1.000 & 0.962 & & -- & -- & -- \\
South Korea & 0.027 & 1.000 & 0.996 & & - & -- & -- \\
Malaysia & 0.016 & 1.000 & 0.860 & & 0.033 & 0.857 & 0.996 \\
Mexico & 0.074 & 0.929 & 0.964 & & 0.068 & 0.929 & 0.968 \\
Marocco & 0.001 & 1.000 & 0.174 & & 0.020 & 0.900 & 0.769 \\
Peru & 0.030 & 1.000 & 0.952 & & 0.019 & 1.000 & 0.977 \\
Philippines & 0.019 & 0.900 & 0.757 & & 0.025 & 0.889 & 0.973 \\
Thailand & 0.019 & 1.000 & 0.977 & & 0.015 & 1.000 & 0.851 \\
Turkey & 0.025 & 0.889 & 0.973 & & 0.021 & 1.000 & 0.813 \\
Uruguay & 0.013 & 1.000 & 0.835 & & 0.000 & 1.000 & 0.000 \\
Venezuela & 0.025 & 0.929 & 0.888 & & 0.061 & 1.000 & 0.956 \\
\hline \hline
\end{tabular}

Note: For each country we identify the optimal cut-off by using the accuracy measures method, so as to give more weight to the correct identification of crisis periods (sensitivity). Cut-off values are in bold. 
TABLE 11 - Evaluation criteria for the dynamic panel logit model

\begin{tabular}{|c|c|c|c|c|c|c|}
\hline \multicolumn{7}{|c|}{ All countries } \\
\hline Country & $\mathrm{AUC}$ & Kuiper score & Pietra index & Bayesian error rate & QPS & LPS \\
\hline Argentina & 0.950 & 0.799 & 0.282 & 0.019 & 0.036 & 0.071 \\
\hline Brazil & 0.806 & 0.594 & 0.210 & 0.038 & 0.082 & 0.155 \\
\hline Chile & 0.475 & 0.307 & 0.108 & 0.011 & 0.026 & 0.069 \\
\hline Indonesia & 0.913 & 0.893 & 0.316 & 0.015 & 0.032 & 0.070 \\
\hline Israel & 0.983 & 0.962 & 0.340 & 0.008 & 0.011 & 0.027 \\
\hline South Korea & 0.999 & 0.996 & 0.352 & 0.004 & 0.013 & 0.032 \\
\hline Malaysia & 0.978 & 0.860 & 0.304 & 0.008 & 0.017 & 0.038 \\
\hline Mexico & 0.924 & 0.893 & 0.316 & 0.023 & 0.044 & 0.097 \\
\hline Marocco & 0.271 & 0.174 & 0.062 & 0.004 & 0.008 & 0.028 \\
\hline Peru & 0.988 & 0.952 & 0.337 & 0.023 & 0.039 & 0.071 \\
\hline Philippines & 0.905 & 0.657 & 0.232 & 0.030 & 0.048 & 0.096 \\
\hline Thailand & 0.994 & 0.977 & 0.345 & 0.008 & 0.016 & 0.036 \\
\hline Turkey & 0.976 & 0.862 & 0.305 & 0.015 & 0.035 & 0.069 \\
\hline Uruguay & 0.964 & 0.835 & 0.295 & 0.015 & 0.035 & 0.073 \\
\hline Venezuela & 0.964 & 0.817 & 0.289 & 0.023 & 0.049 & 0.095 \\
\hline \multicolumn{7}{|c|}{ Poolable countries } \\
\hline Country & $\mathrm{AUC}$ & Kuiper score & Pietra index & Bayesian error rate & QPS & LPS \\
\hline Argentina & 0.950 & 0.787 & 0.278 & 0.019 & 0.036 & 0.071 \\
\hline Brazil & 0.810 & 0.598 & 0.211 & 0.038 & 0.081 & 0.153 \\
\hline Chile & 0.443 & 0.299 & 0.106 & 0.011 & 0.025 & 0.069 \\
\hline Indonesia & 0.913 & 0.893 & 0.316 & 0.015 & 0.032 & 0.069 \\
\hline Israel & -- & -- & -- & -- & -- & -- \\
\hline South Korea & -- & -- & -- & -- & -- & -- \\
\hline Malaysia & 0.977 & 0.853 & 0.302 & 0.008 & 0.017 & 0.039 \\
\hline Mexico & 0.923 & 0.897 & 0.317 & 0.023 & 0.044 & 0.095 \\
\hline Marocco & 0.910 & 0.669 & 0.236 & 0.030 & 0.048 & 0.096 \\
\hline Peru & 0.994 & 0.977 & 0.345 & 0.008 & 0.016 & 0.037 \\
\hline Philippines & 0.977 & 0.862 & 0.305 & 0.015 & 0.035 & 0.070 \\
\hline Thailand & 0.965 & 0.851 & 0.301 & 0.015 & 0.035 & 0.073 \\
\hline Turkey & 0.965 & 0.813 & 0.287 & 0.023 & 0.049 & 0.096 \\
\hline Uruguay & 0.167 & 0.000 & 0.000 & 0.004 & 0.008 & 0.032 \\
\hline Venezuela & 0.989 & 0.956 & 0.338 & 0.023 & 0.037 & 0.062 \\
\hline
\end{tabular}

Note: The AUC criteria takes values between 0.5 and 1, 1 being the perfect model. Kuiper's score should have positive values if the model identifies well the crisis periods. Pietra index takes values from - 0.354 to 0.354 , the higher its level, the better the model. Bayesian error rate takes values between 0 and 1, 0 corresponding to the perfect model. QPS ranges from 0 to 2,0 being perfect accuracy, while LPS ranges from 0 to $\infty, 0$ being perfect accuracy. For Malaysia and Morocco time-series analyses have been performed the results being available in table 11 . 
TABLE 12 - Comparison test of dynamic time-series and panel logit models

\begin{tabular}{lccccc}
\hline \hline \multirow{2}{*}{ Country } & \multicolumn{2}{c}{ Time series vs Panel - All countries } & & \multicolumn{2}{c}{ Time series vs Panel - Poolable countries } \\
\cline { 2 - 3 } \cline { 5 - 6 } test statistic & p-value & & test statistic & p-value \\
\hline Argentina & 0.715 & 0.474 & & 0.662 & 0.508 \\
Brazil & 1.496 & 0.135 & & 1.491 & 0.136 \\
Chile & 1.343 & 0.179 & & 1.391 & 0.164 \\
Indonesia & 1.402 & 0.161 & & 1.431 & 0.152 \\
Israel & 0.139 & 0.889 & & -- & -- \\
South Korea & 1.304 & 0.192 & & -- & -- \\
Malaysia & 0.782 & 0.434 & & 0.803 & 0.422 \\
Mexico & 0.834 & 0.404 & & 0.801 & 0.423 \\
Marocco & 1.033 & 0.302 & & 2.320 & $\mathbf{0 . 0 2 0}$ \\
Peru & 0.138 & 0.890 & & -1.446 & 0.148 \\
Philippines & -0.059 & 0.953 & & -0.651 & 0.515 \\
Thailand & 0.863 & 0.388 & & 1.541 & 0.123 \\
Turkey & -0.832 & 0.406 & & 1.075 & 0.282 \\
Uruguay & 0.160 & 0.873 & -1.746 & 0.081 \\
Venezuela & 0.755 & 0.450 & -2.308 & $\mathbf{0 . 0 2 1}$ \\
\hline \hline
\end{tabular}

Note: The null hypothesis of the Diebold Mariano test is the equality of predictive performance of the two models. The alternative indicates that the first model is better than the other one. Under the null hypothesis, the test statistic follows a normal distribution. Bold entries indicate significance at the $5 \%$ level.

TABLE 13 - Optimal cut-off identification (Out-of-sample exercise)

\begin{tabular}{lccc}
\hline \hline & Cut-off & Sensitivity & Specificity \\
\hline One-month-ahead forecasts & & & \\
Argentina & 0.011 & 0.8 & 0.938 \\
Brazil & 0.11 & 0 & 0.992 \\
Chile & 0.021 & 0 & 0.812 \\
Philippines & 0.065 & 0.625 & 0.857 \\
Uruguay & 0.028 & 0.875 & 0.944 \\
Venezuela & 0.162 & 0 & 0.977 \\
24-months-ahead forecasts & & & \\
Argentina & 0.001 & 0.964 & 0.434 \\
Brazil & 0.026 & 0.958 & 0.809 \\
Chile & 0.170 & 1.000 & 0.991 \\
Indonesia & 0.664 & 1.000 & 0.983 \\
South Korea & 0.032 & 1.000 & 0.949 \\
Malaysia & 0.040 & 1.000 & 0.992 \\
Philippines & 0.126 & 0.974 & 0.969 \\
Thailand & 0.130 & 1.000 & 0.967 \\
Turkey & 0.020 & 0.964 & 0.840 \\
Uruguay & 0.083 & 0.968 & 0.971 \\
Venezuela & 0.131 & 0.958 & 0.945 \\
\hline \hline
\end{tabular}

Note: For each country we identify the optimal cut-off by using the accuracy measures method, so as to give more weight to the correct identification of crisis periods (sensitivity). The values of the cut-off are calculated on the basis of the in-sample dataset (January 1986 - December 1996). The other countries, i.e. Israel, South Korea, Malaysia, Mexico, Morocco, Peru, Thailand and turkey do not register any in sample or out-of-sample crises. 
TABLE 14 - Evaluation criteria for the out-of-sample dynamic logit model

\begin{tabular}{lcccccc}
\hline \hline Country & AUC & Kuiper score & Pietra index & Bayesian error rate & QPS & LPS \\
\hline One-month-ahead forecasts & & & & & & \\
Argentina & 0.874 & 0.738 & 0.280 & 0.015 & 0.054 & 0.260 \\
Brazil & 0.737 & -0.008 & 0.261 & 0.007 & 0.023 & 0.055 \\
Chile & 0.545 & -0.188 & 0.183 & 0.007 & 0.018 & 0.062 \\
Philippines & 0.690 & 0.482 & 0.207 & 0.045 & 0.094 & 2.914 \\
Uruguay & 0.915 & 0.819 & 0.307 & 0.015 & 0.047 & 0.244 \\
Venezuela & 0.372 & -0.023 & 0.000 & 0.007 & 0.019 & 5.135 \\
24-months-ahead forecasts & & & & & & \\
Argentina & 0.947 & 0.398 & 0.325 & 0.022 & 0.045 & 1.504 \\
Brazil & 0.985 & 0.767 & 0.336 & 0.015 & 0.032 & 0.081 \\
Chile & 0.992 & 0.991 & 0.350 & 0.007 & 0.015 & 0.076 \\
Indonesia & 0.993 & 0.983 & 0.351 & 0.007 & 0.024 & 0.172 \\
South Korea & 0.996 & 0.949 & 0.351 & 0.007 & 0.015 & 0.147 \\
Malaysia & 0.996 & 0.992 & 0.351 & 0.007 & 0.015 & 0.087 \\
Philippines & 0.973 & 0.942 & 0.341 & 0.015 & 0.043 & 0.126 \\
Thailand & 0.994 & 0.967 & 0.345 & 0.015 & 0.049 & 0.131 \\
Turkey & 0.971 & 0.804 & 0.338 & 0.015 & 0.030 & 0.081 \\
Uruguay & 0.966 & 0.939 & 0.339 & 0.015 & 0.030 & 3.115 \\
Venezuela & 0.957 & 0.904 & 0.336 & 0.015 & 0.037 & 0.187 \\
\hline \hline
\end{tabular}

Note: The AUC criteria takes values between 0.5 and 1, 1 being the perfect model. Kuiper's score should have positive values if the model identifies well the crisis periods. Pietra index takes values from - 0.354 to 0.354, the higher its level, the better the model. Bayesian error rate takes values between 0 and 1, 0 corresponding to the perfect model. QPS ranges from 0 to 2,0 being perfect accuracy, while LPS ranges from 0 to $\infty, 0$ being perfect accuracy. 